\title{
The mitotic spindle is required for loading of the DASH complex onto the kinetochore
}

\author{
Yumei Li, ${ }^{1}$ Jeff Bachant, ${ }^{1}$ Annette A. Alcasabas, ${ }^{1}$ Yanchang Wang, ${ }^{1}$ Jun Qin,,${ }^{1,2}$ \\ and Stephen J. Elledge ${ }^{1,3,4,5}$ \\ ${ }^{1}$ Verna and Marrs McLean Department of Biochemistry and Molecular Biology, ${ }^{2}$ Department of Cell Biology, ${ }^{3}$ Department \\ of Molecular and Human Genetics, ${ }^{4}$ Howard Hughes Medical Institute, Baylor College of Medicine, \\ Houston, Texas 77030, USA
}

\begin{abstract}
A role for the mitotic spindle in the maturation of the kinetochore has not been defined previously. Here we describe the isolation of a novel and conserved essential gene, ASK1, from Saccharomyces cerevisiae involved in this process. ask1 mutants display either $G_{2} / M$ arrest or segregation of DNA masses without the separation of sister chromatids, resulting in massive nondisjunction and broken spindles. Ask1 localizes along mitotic spindles and to kinetochores, and cross-links to centromeric DNA. Microtubules are required for Ask1 binding to kinetochores, and are partially required to maintain its association. We found Ask1 is part of a multisubunit complex, DASH, that contains $\sim 10$ components, including several proteins essential for mitosis including Dam1, Duo1, Spc34, Spc19, and Hsk1. The Ipl1 kinase controls the phosphorylation of Dam1 in the DASH complex and may regulate its function. We propose that DASH is a microtubule-binding complex that is transferred to the kinetochore prior to mitosis, thereby defining a new step in kinetochore maturation.
\end{abstract}

[Key Words: Ask1; spindle; kinetochore; chromosome segregation]

Received November 2, 2001; revised version accepted November 27, 2001.

Mitosis is the period of the cell cycle during which chromosomes are segregated to daughter cells through the process of anaphase. The ability to accurately distribute replicated chromosomes is critical for the proper transfer of genetic material from one generation to the next. Errors in this process can lead to developmental defects, cancer, or death. Cells ensure the fidelity of this process through multiple layers of control that operate during mitosis.

The physical movement of chromosomes during anaphase is carried out by the mitotic spindle. The mitotic spindle is a bipolar microtubule-based structure that emanates from two organizing centers, called centrosomes or spindle-pole bodies (SPB), and connects to chromosomes (Hoyt and Geiser 1996; Winey and O'Toole 2001). The mitotic spindle binds to newly replicated chromosomes (called sister chromatids), but chromosome segregation does not take place until cohesion along the sister chromatids is eliminated. The elimination of cohesion is a highly regulated step that is cata-

${ }^{5}$ Corresponding author.

E-MAIL seledge@bcm.tmc.edu; FAX (713) 798-8717.

Article and publication are at http://www.genesdev.org/cgi/doi/10.1101/ gad.959402. lyzed by a protease, Esp1, which is activated by the destruction of its inhibitor, Pds1 (Cohen-Fix et al. 1996; Ciosk et al. 1998; Uhlmann et al. 1999).

Anaphase does not occur until all chromosomes form a bipolar attachment with the spindle. A centromerebased mitotic checkpoint system referred to as the spindle checkpoint (Amon 1999) monitors spindle-chromosome interactions and blocks anaphase until all sister chromatids have successfully attached to spindle microtubules in a bipolar fashion (Wang and Burke 1995; Pangilinan and Spencer 1996). In budding yeast, at least six genes, MAD1-MAD3, BUB1, BUB3, and MPS1 (Hoyt et al. 1991; Li and Murray 1991; Hardwick and Murray 1995; Hardwick et al. 1996; Farr and Hoyt 1998), are required for the spindle checkpoint to prevent anaphase. When active, the spindle checkpoint prevents anaphase by inhibiting the ubiquitin-mediated degradation of anaphase inhibitor Pds1/Cut2 (Cohen-Fix et al. 1996; Funabiki et al. 1996; Yamamoto et al. 1996; Hwang et al 1998; Kim et al. 1998).

How the spindle forms, recognizes, and binds to chromosomes is currently a topic of extensive research. Several proteins are known to be associated with spindles and play important functions in spindle assembly and dynamics. These proteins include motor proteins, such 
as Kar3, Kip1, and Cin8 (Hoyt et al. 1992; Roof et al. 1992; Saunders and Hoyt 1992), and other microtubule associated proteins, such as Ase1 (Pellman et al. 1995) and Esp1 (Jensen et al. 2001).

The spindle microtubules attach to chromosomes through the kinetochore, a specialized structure consisting of the centromeric DNA and its associated proteins (Lechner and Ortiz 1996; Pidoux and Allshire 2000). In budding yeast, the centromere (CEN) is a short sequence consisting of three well-conserved elements important for centromere function, CDEI, CDEII, and CDEIII. CDEIII and at least part of CDEII are indispensable for centromere function (Hegemann and Fleig 1993). Several kinetochore proteins have been identified that bind to a specific centromere region. Cbfl binds to CDEI and is involved in the fidelity of chromosome transmission (Cai and Davis 1990). Ndc10 (Doheny et al. 1993; Goh and Kilmartin 1993; Jiang et al. 1993), Ctf13 (Doheny et al. 1993), Cep3 (Lechner 1994; Strunnikov et al. 1995), and Skp1 (Connelly and Hieter 1996) bind to CDEIII as a multisubunit protein complex (CBF3). In addition, Cse4 (Meluh et al. 1998), a homolog of CENP-A, is hypothesized to be involved in the formation of the specialized centromere nucleosome. Mif2 (Meluh and Koshland 1995, 1997), a homolog of CENP-C, interacts with CEN DNA in a CDEIII-dependent manner. Other proteins, such as Ctf19, Mcm21, and Okp1 are also important for the formation of the kinetochore (Hyland et al. 1999; Ortiz et al. 1999).

Once the kinetochore is attached by microtubules, it is likely that mechanisms exist to alter its properties. One piece of evidence supporting this hypothesis is the presence of a particular phosphorylation event recognized by the 3F3/2 antibody localized specifically to the kinetochores of unattached chromosomes (Gorbsky and Ricketts 1993). Further evidence comes from the presence of the Mad2 protein on these same chromosomes, presumably signaling to prevent anaphase entry (Chen et al. 1996). It is unknown how the kinetochore is altered by microtubule attachment. Presumably, there is a signaling event, possibly a structural change, that alters the kinetochore once a microtubule is bound. Other changes may also accompany binding such as strengthening of the attachment itself pursuant to segregation and possibly signaling from the kinetochore to the spindle to regulate spindle dynamics in cis. In this study, we describe the identification of a novel protein, Ask1 (associated with spindles and kinetochores), required for maintaining proper kinetochore-microtubule attachments and chromosome segregation. Our data suggests that Ask1 initially binds to microtubules and subsequently binds kinetochores upon microtubule attachment during $\mathrm{S}$ phase, when new kinetochores are assembled. We discovered that Ask1 is part of a complex we call DASH that contains multiple essential proteins. The Ipll kinase controls the phosphorylation of a component of the DASH complex, Dam1, and may regulate its function. Thus, the DASH complex may alter the property of the kinetochore to allow it to achieve its mature spindlebound form.

\section{Results}

The ask1-1 mutant is defective in maintaining spindle integrity in $\mathrm{HU}$

To identify genes involved in the restraint of anaphase entry during S-phase arrest, a genetic screen was conducted to search for mutants that have an elongated spindle phenotype in the presence of hydroxyurea (HU), an inhibitor of DNA replication. Whereas wild-type cells arrested with HU show short spindles, mutants isolated from the screen display elongated spindles in the presence of HU (Alcasabas et al. 2001). Among several mutants isolated from the screen was ask1-1. ask1-1 mutant cells failed to grow on plates containing $150 \mathrm{mM} \mathrm{HU}$ (Fig. 1A). Cells lost viability over time when incubated in $\mathrm{HU}$, indicating that they were undergoing a catastrophic event (Fig. 1B). To investigate whether ASK1 is involved in the replication checkpoint pathway, we examined two well-characterized checkpoint responses in ask1-1 mutant cells, Rad53 hyperphosphorylation and RNR3 transcriptional induction (Elledge and Davis 1990; Sanchez et al. 1996). To examine Rad53 phosphorylation, extracts of wild-type or ask1-1 mutants were prepared from cells treated with $200 \mathrm{mM} \mathrm{HU}$ or $0.5 \%$ MMS, and Western blotting was carried out using anti-Rad53 antibodies. In both wild-type and ask1-1 mutant cells, modification of Rad53 was observed upon HU or MMS treatment (Fig. 1C). The transcriptional induction of $R N R 3$ was also examined under similar conditions and found to be fully intact (data not shown). Thus, we were unable to establish a connection between Ask1 and known components of the replication checkpoint pathway, indicating that Ask1 is either a downstream effector in this pathway or that Ask1 is part of an independent mechanism required for the maintenance of spindle integrity during a prolonged S-phase arrest.

\section{ASK1 is an essential gene encoding a novel protein}

ASK1 (YKL052C) was cloned by complementing the HU sensitivity of the ask1-1 mutants. It encodes a protein of 293 amino acids with no obvious conserved motifs. Database analysis identified sequence homologs present in Schizosaccharomyces pombe (SPBC27.02c) and Drosophila melanogaster (Fig. 1D). Deletion of ASK1 was performed in diploid cells by gene replacement. Tetrad dissection revealed that the ask 1 null mutant is inviable and is genetically linked to the original ask1-1 mutation (data not shown).

To investigate the function of $A S K 1$, conditional alleles of ASK1 were generated by PCR mutagenesis. Six temperature-sensitive alleles were isolated and used to replace the endogenous ASK1 gene. The phenotypes of these mutants were investigated by use of synchronous cultures. Cells were arrested at $\mathrm{G}_{1}$ with $\alpha$-factor at $25^{\circ} \mathrm{C}$, and then shifted to $37^{\circ} \mathrm{C}$ for 30 min before release from the block. On the basis of DNA and spindle morphologies, the six temperature-sensitive alleles can be divided into two classes. One class contains a single allele, ask12, which arrested as large budded cells with a $2 \mathrm{~N}$ DNA 
A

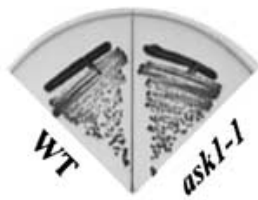

YPD

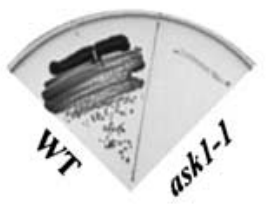

YPD+150 mM HU

C

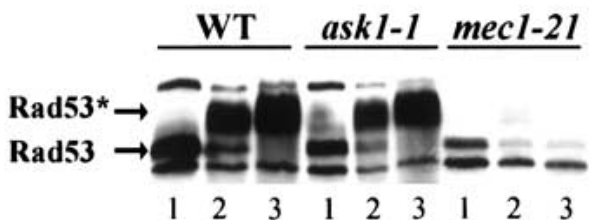

Spindle-dependent loading of DASH onto kinetochore

B

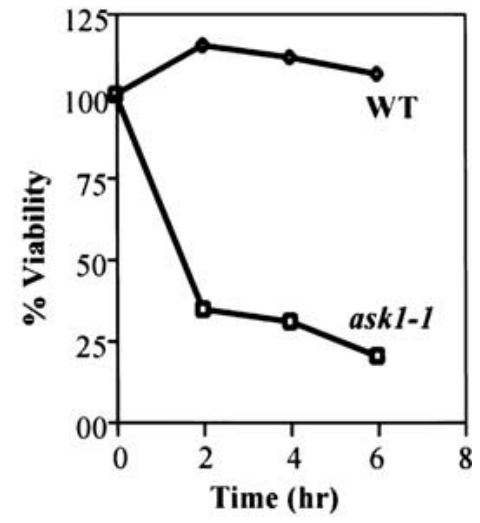

D S.cerevisiae

S.pombe

D. melanogaster

1 - - - - - - MDSA SKEETLEKLVQEITVNLQK - IDSNLSFC- - FHKITQ

1 - - - - - - MNNLEQLERLEQSITLALYE-IDANFSKC- - - HRTVTT

201 KVIEQKVCEHTEKKADESLSKDQQKDSITFGTCVRERIHHLELEMEKCTE

S.cerevisiae 38 DIIPHVATYSEICERTMDSTEWLGTMFQETGLVNLQA--NAAAPV- -GNA

S.pombe 35 KII I IVKYAKNCNTIWDS SKF WKQFEEASANVSL SGV-EEPVPVE-SNP

D. melanogaster 251 ELVDFVELNADVLN-YANVSTHLKKLQRSKESDEKDEDDRRALEEGIGGP

S.cerevisiae 84 PVKSLVSNNVG IFPT SAEEASRQSQTDNG PNEADSAVHVNRDV-HSMF - -

S.pombe 83 SDQDVMSN---.--STEADLQLHTKNEHLEKRHSFVGKSDFPDAAVQG

D. melanogaster 300 GSQNY----E I F RQE--QEKERQRQVQE F LARDETNEYDNLDLDHAY---

S.cerevisiae 131 NNDSIDDFHTANITSTGQILKLP--DSSDEDTGSEAVPSREQTDL-TGE-

S.pombe 125 DNTKNEDF- - - VQSTPKKMDVSLEDISLDDAALTPIPARMQTPLRK PEN

D. melanogaster

341 - - -RAKYYT - -AYKE IGKELNPA - PDSGGRDSGSEH SPGRDN- - - - - Y

S.cerevisiae

S.pombe

D. melanogaster

177 - - - -GHGGADDEQDESTIQRQSRKRKI SLLLQQQY - - GSSSSMV-PSP IV

171 NPHTGRSALLHRVLDTNWQVQVTPREPKNLQSQEVMDIDSSPFVSPSPI-

378 - - - - TTYADYFLKYTTPQQNWNDLERANGLQREH - - - DRIYGLFW- - -L-

S.cerevisiae

S.pombe

220 PNKMRKQLAHEEH INND- - - - - GDNDDEN S NNTE SSPL - - KQGHHHPK

220 - - SMKMDMP S LNDRNS SHAL S L FAEFEHESY DSIN PSGMS P PKT I QF SPH

D. melanogaster

417 - - - NDRRQEEKYRRK - - - LAQNDQEELPVHHHKAC - - RHRHHKPN

S.cerevisiae 261 GQADDNNEGPDEEESTKEVPKPGTIIHFSTNR-- - - - -

S.pombe 268 TMGVGSSQQANERSLSLQRKLETLNDSNDSFVKEEDSWEL

D. melanogaster 454 HHAPYDHMRPTEDDIQEADSLPESN-

Figure 1. Characterization of ask1-1 mutant cells. (A) ask1-1 mutants are HU sensitive. Wild-type (Y300) and ask1-1 (Y928) mutants were streaked on YPD plates containing $150 \mathrm{mM} \mathrm{HU}$ at $30^{\circ} \mathrm{C}$ and incubated for $3 \mathrm{~d}$. (B) ask1-1 loses viability in HU. $\alpha$-factor arrested wild-type (Y300) and ask1-1 (Y928) mutant cells were released into YPD containing $200 \mathrm{mM}$ HU for the indicated times and plated on YPD at $30^{\circ} \mathrm{C}$ to determine survival. (C) Proper regulation of Rad53 in ask1-1 mutants. Log-phase cells of wild-type (Y300), ask1-1 (Y928), and mec1-21 (Y604) were treated with $200 \mathrm{mM} \mathrm{HU}$ (lane 2) or 0.5\% MMS (lane 3) for $1.5 \mathrm{~h}$ at $30^{\circ} \mathrm{C}$. Protein extracts were prepared, separated by SDS/PAGE, and immunoblotted with antibodies against Rad53. (Lane 1) Untreated control. (D) Alignment of S. cerevisiae Ask1 protein with its homologs from S. pombe and D. melanogaster. Identical residues are highlighted in black and conserved residues in gray.

content, undivided nuclei, and short spindles (Fig. 2A). These mutant cells maintained their viability when incubated at $37^{\circ} \mathrm{C}$ (data not shown). The remaining temperature-sensitive alleles fall into the second class, whose representative mutant is ask1-3. When ask1-3 mutant cells were released from $G_{1}$ arrest at the restrictive temperature $\left(35^{\circ} \mathrm{C}\right)$, they arrested temporarily with a $2 \mathrm{~N}$ DNA content for $\sim 120$ min before some $G_{1}$ cells reappeared (Fig. 2B). Cells analyzed at the 90-min time point showed unusually stretched DNA masses and an abnormal spindle morphology - the microtubule staining between the two SPBs was greatly reduced and the SPBs are further apart relative to normal preanaphase SPBs (Fig. 2B). Meanwhile, the viability of ask1-3 mutant cells began to decline at $60 \mathrm{~min}$ after release (data not shown). 
A

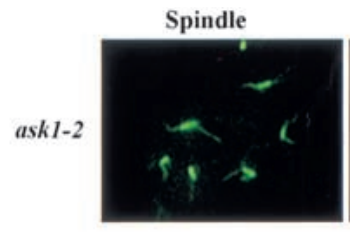

B
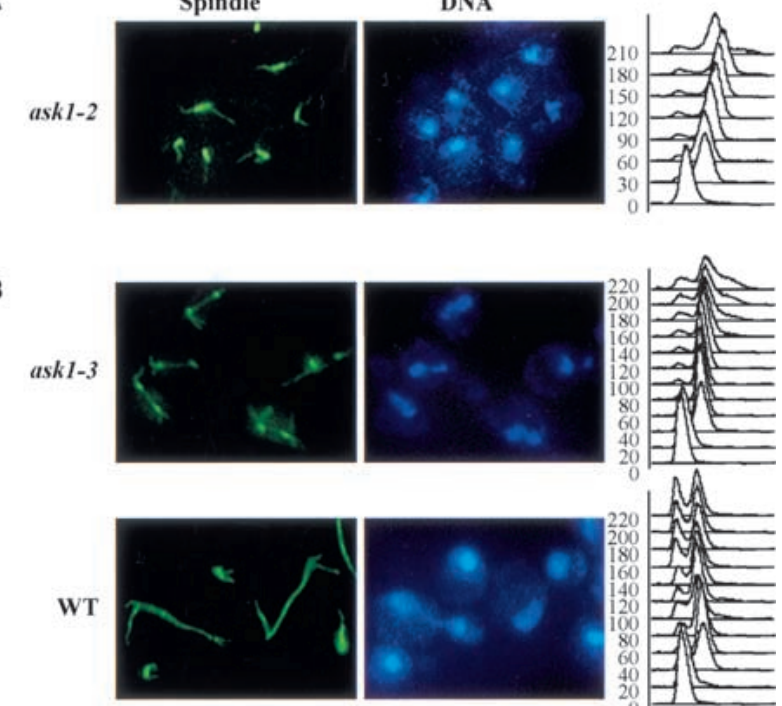

C
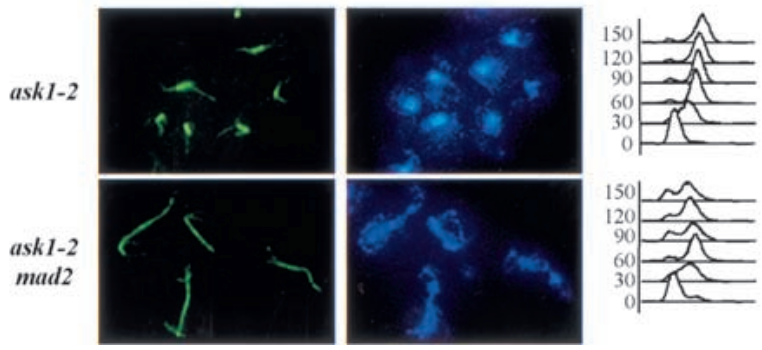

15

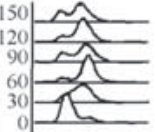

Figure 2. Characterization of temperature-sensitive alleles of ASK1. (A) ask1-2 mutant cells arrest before anaphase entry. ask1-2 mutant cells (Y1104) were synchronized by $\alpha$-factor and released into YPD at $37^{\circ} \mathrm{C}$. (Left) The DNA and spindle morphology of ask1-2 cells at 90 min following the release. (Right) The DNA content determined by FACS analysis. (B) ask1-3 mutants display unusual spindle phenotypes at the restrictive temperature. Wild-type (Y300) and ask1-3 (Y1103) mutant cells were synchronized by $\alpha$-factor and released at $35^{\circ} \mathrm{C}$. At the indicated times after the release, aliquots were withdrawn to examine viability, DNA content, and nuclear spindle morphology. Photomicrographs show wild-type and ask1-3 mutant cells at 90 min after release. (C) ask1-2 (Y1104) and ask1-2 mad2 (Y1106) mutant cells were synchronized and released as in $A$. Aliquots were collected for FACS analysis, DNA, and spindle staining at the indicated times. Photomicrographs were taken of cells at $90 \mathrm{~min}$ after the release.

\section{The spindle checkpoint is activated in ask1-2 mutants}

Anaphase entry is tightly regulated by checkpoints. Activation of either the DNA damage checkpoint or the spindle checkpoint leads to preanaphase arrest. To determine the cause of arrest in ask1-2 mutants, double mutants of ask1-2 with either rad9 or mad2 were constructed. RAD9 is a key component of DNA damage checkpoint, whereas MAD2 is required for the spindle checkpoint pathway. In synchronous cultures, ask1-2 rad9 mutant cells arrested as large budded cells with a $2 \mathrm{~N}$ DNA content at the restrictive temperature (data not shown), indicating that ask1-2 mutants do not require the DNA damage checkpoint for arrest. In contrast, ask1-2 mad2 double mutants failed to arrest and attempted to segregate chromosomes with elongated spindles (Fig. 2C). Thus, ask1-2 mutants activate the spindle checkpoint to cause a preanaphase arrest.

\section{ask1-3 mutants undergo massive nondisjuction without sister chromatid separation}

The ask1-3 class of mutants appear to be more severe than ask1-2 mutants and would therefore be expected to also activate the spindle checkpoint. Yet, ask1-3 mutants appear to segregate chromosomes and eventually exit mitosis (Fig. 2B, 220-min timepoint). To explore this hypothesis, we examined several aspects of spindle checkpoint function in ask1-3 mutants including the phenotypic consequences of mad2 mutants, the degradation of Pds1, and sister chromatid segregation.

To examine the effects of mad2 on the phenotype of ask1-3 mutants, the ask1-3 mad2 double mutant was constructed and its cell cycle progression was examined in synchronous cultures at $35^{\circ} \mathrm{C}$. ask 1-3 mutant cells displayed delayed mitotic progression. Cells with $1 \mathrm{~N}$ DNA content did not reappear, even at 150 min after $G_{1}$ release. However, ask1-3 mad2 double mutant cells progressed through mitosis without delay (FACS, Fig. 3A) and $G_{1}$ cells reappeared around 90 min after release, similar to mad2 cells. In addition, the abnormal spindle defects evident in ask1-3 mutants were no longer observed in the double mutants (Fig. 3A), suggesting that the spindle checkpoint is also active in ask1-3 mutants and has a profound effect on the spindle phenotype of these cells. However, unequal distribution of chromatin was still evident in these ask1-3 mad2 cells, indicating a defect in anaphase.

Pds1 is an inhibitor of Esp1, the protease that cleaves the Mcd1/Scc1 cohesin subunit. Pds1 is an ubiquitylation substrate of the anaphase promoting complex (APC) and its degradation is required for cells to enter anaphase. Both wild-type and ask1-3 mutant cells carrying Pds1-18xMyc were analyzed for Pds1 protein levels. Cells were arrested at $\mathrm{G}_{1}$, shifted to $35^{\circ} \mathrm{C}$ for $30 \mathrm{~min}$, and then released. Fifty-five minutes after the release, $\alpha$-factor was added back to prevent cells from entering the next cell cycle. In wild-type cells, Pds1 levels increased $30 \mathrm{~min}$ after release, and declined by $75 \mathrm{~min}$. In ask1-3 mutant cells, Pds1 levels were maintained at high levels throughout the experiment, indicating that Pds1 was stabilized in ask1-3 mutant cells, presumably due to the activation of spindle checkpoint (Fig. 3B).

If Pds1 levels remain high through activation of the spindle checkpoint, then cohesion should also be maintained unless ASK1 plays a role in the cohesion process itself. To address this, we followed sister-chromatid separation using GFP-marked chromosomes (Michaelis et al. 1997). $\alpha$-factor arrested wild-type, ask1-3, and ask1-3 mad2 mutant cells were followed over time after release at $35^{\circ} \mathrm{C}$. In both wild-type and ask1-3 mad2 cells, sister-chromatid separation began between 60 and 90 min after release. However, in ask1-3 mutants, despite the segregated DNA masses, sister chromatids failed to 
A

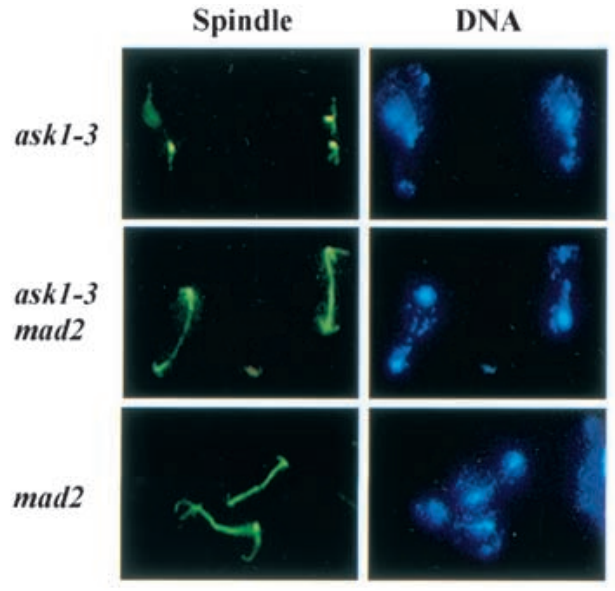

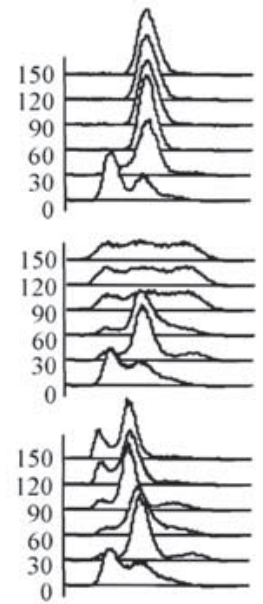

B Time

(minute) ๑

WT $\quad=$

ask $1-3$

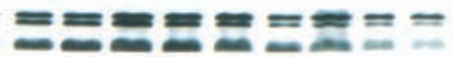

C

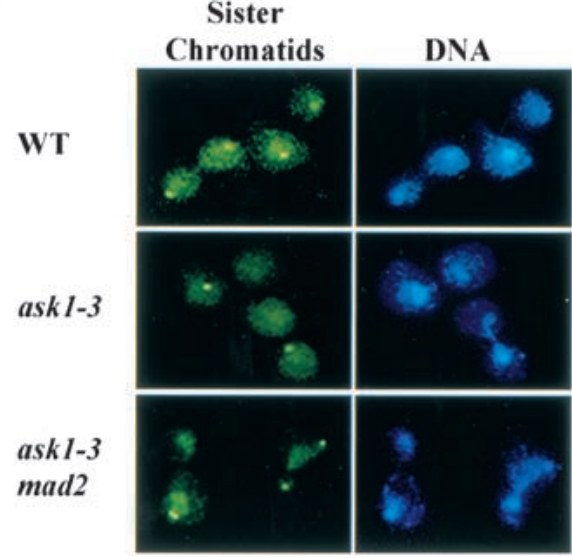

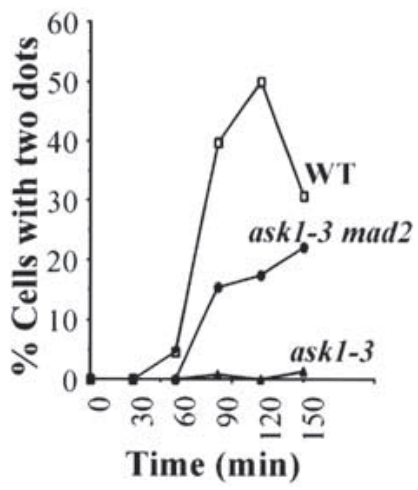

Figure 3. ask1-3 mutants undergo massive nondisjunction and segregate chromosomes without the separation of sister chromatids. (A) The spindle checkpoint is active in ask1-3 mutants. ask1-3 (Y1103), ask1-3 mad2 (Y1107), and mad2 (Y1101) mutants were arrested in $\mathrm{G}_{1}$ with $\alpha$-factor and then released at $35^{\circ} \mathrm{C}$. Ninety minutes after the release, samples were collected and stained with DAPI (DNA) and anti-tubulin antibodies (spindles). (B) Pds1 is stabilized in ask1-3 mutants. Wild-type (Y998) and ask1-3 mutant (Y1108) cells carrying the PDS1 gene fused to 18 copies of the myc epitope were synchronized with $\alpha$-factor at $24^{\circ} \mathrm{C}$ and then released at $35^{\circ} \mathrm{C}$. Cells were harvested every $15 \mathrm{~min}$ and processed for protein preparation. Pds1 levels were determined by Western blotting using anti-Myc antibodies. (C) Analysis of sister-chromatid separation in arrested ask1-3 mutant cells. Wild-type (Y974), ask1-3 mutant (Y1109), and ask1-3 mad2 (Y1110) cells containing a Tet-GFP fusion and tandem repeats of the Tet operator integrated at the URA3 locus $35 \mathrm{~kb}$ away from centromere on the left arm of ChrV were synchronized by $\alpha$-factor at $24^{\circ} \mathrm{C}$ and then released at $35^{\circ} \mathrm{C}$. Ninety minutes after release, samples were collected to examine sister chromatid separation by immunofluorescence microscopy. separate even at $150 \mathrm{~min}$ after release (Fig. 3C). Thus, ask1-3 mutant cells undergo premature segregation of chromosome without the separation of sister chromatids, leading to massive nondisjunction. In addition, in ask1-3 mad2 cells, although sister chromatids separated, $60 \%$ of the time both sisters remained in one cell body and failed to segregate. This form of nondisjunction is consistent with a defect in bipolar spindle attachment.

\section{Ask1 associates with centromeres in vivo}

Cellular localization is often indicative of protein function. Ask1 was tagged with GFP at its carboxyl terminus and integrated at the ASK1 locus of wild-type cells. Indirect immunofluorescence microscopy was performed using DAPI, antibodies against GFP, and tubulin to visualize DNA, Ask1p, and spindles, respectively. A dotlike GFP signal was clearly seen in cells of all cell cycle stages. A single dot was seen in $\mathrm{G}_{1}$ cells. Later, when cells set up and elongated the spindles, two dots were observed in the vicinity of the spindle pole bodies. Ask1 staining was also found along the mitotic spindle in preanaphase and during anaphase B (Fig. 4A). The same result was obtained using strains in which Ask1 was tagged with nine copies of the Myc-epitope at its carboxyl terminus (data not shown).

During mitosis, centromeres of sister chromatids transiently separate toward the opposite ends of spindles and localize very close to the SPBs (Goshima and Yanagida 2000; He et al. 2000). To examine whether Ask1 is localized at the SPB or the kinetochore, the localization of Ask1 was examined in a ndc10-1 mutant background. $\mathrm{Ndc10}$ is an essential kinetochore component. ndc10-1 mutants elongate spindles without segregating the chromosomes. Cells were grown to mid-log phase at $24^{\circ} \mathrm{C}$ and synchronized in $\mathrm{G}_{1}$ using $\alpha$-factor. After release at $35^{\circ} \mathrm{C}$, cells were collected for immunofluorescence staining. In ndc10-1 mutants, the staining of Ask1 along 
Figure 4. Ask1 is a centromere binding protein. (A) Ask1 localizes to the mitotic spindle and spindle-pole bodies. Cells carrying an integrated ASK1-GFP gene (Y1111) were synchronized in $\mathrm{G}_{1}$ with $\alpha$-factor and released at $30^{\circ} \mathrm{C}$. Samples at different stages of the cell cycle were fixed with $5 \%$ formaldehyde for 30 min before immunofluorescence staining. (B) Localization of Ask1 in wild-type and ndc10-1 mutants. $\mathrm{G}_{1}$-arrested wild-type (Y1111) and ndc10-1 (Y1112) cells containing Ask1-GFP were released into $35^{\circ} \mathrm{C}$ for immunofluorescence microscopy. Representative telophase cells are shown. (C) Chromatin immunoprecipitation analysis (ChIP) of Ask1Myc in wild-type (Y1113) and ndc10-1 (Y1115) cells. Untagged wild-type (Y300) cells (U) are included as control. Log-phase cultures were shifted to $35^{\circ} \mathrm{C}$ for $3 \mathrm{~h}$ before collecting samples. $(D)$ Synthetic growth defects in ask1-3 ndc10-1 double mutants (Y1120). Tenfold dilutions of cells were spotted on plates incubated at $24^{\circ} \mathrm{C}$ and $30^{\circ} \mathrm{C}$. (E) ask1-3 mutants exhibit elevated rates of chromosome loss. Wild-type (Y1117) or ask1-3 mutant (Y1118) strains harboring CFIII were grown in SC-uracil medium at $24^{\circ} \mathrm{C}$ and then plated out on YPD plates at $32^{\circ} \mathrm{C}$ and incubated for $4 \mathrm{~d}$. Red sectors represent chromosome loss events.

the spindle was still present, however, the dot-like SPB localization was no longer observed in telophase cells; instead, there was a diffuse nuclear staining (Fig. 4B). Thus, the dot-like localization of Ask1 depended on Ndc10 and raised the possibility that Ask1 associates with the kinetochore.

To test this hypothesis, we used the chromatin immunoprecipitation (ChIP) assay. Formadehyde cross-linked chromatin prepared from ASK1-MYC and untagged control strains were sonicated and immunoprecipitated with anti-Myc antibodies. The DNA bound to Ask1 was analyzed by PCR using specific primers. Two CEN DNA sequences were tested, CEN3 and CEN16, and both were found enriched in the Ask1-Myc immunoprecipitates, but not in the untagged control strain. The noncentromeric region PGK1 was analyzed as control and was not found in the Ask1-Myc immunoprecipitates (Fig. 4C). This suggested that Ask1 specifically associates with centromeres. Because the dot-like localization of Ask1 depends on Ndc10, we also examined the centromere binding of Ask1 in the ndc10-1 mutant background. Untagged control, wild-type ASK1-MYC and ndc10-1 ASK1-MYC strains were shifted to $35^{\circ} \mathrm{C}$ for $3 \mathrm{~h}$ before the collection of samples. ChIP analysis revealed that the centromere binding of Ask1 is significantly de-

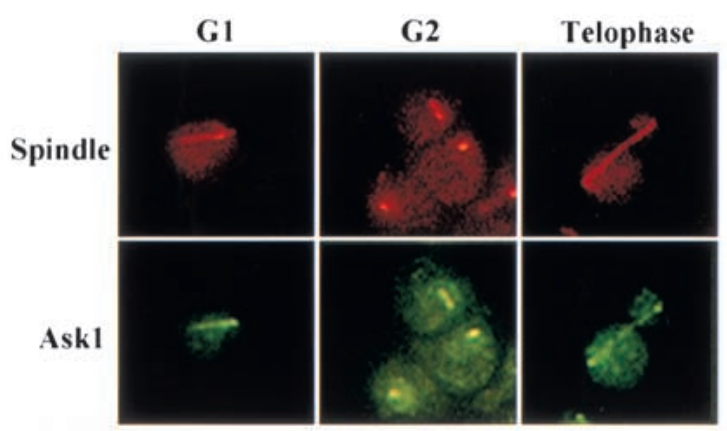

WT
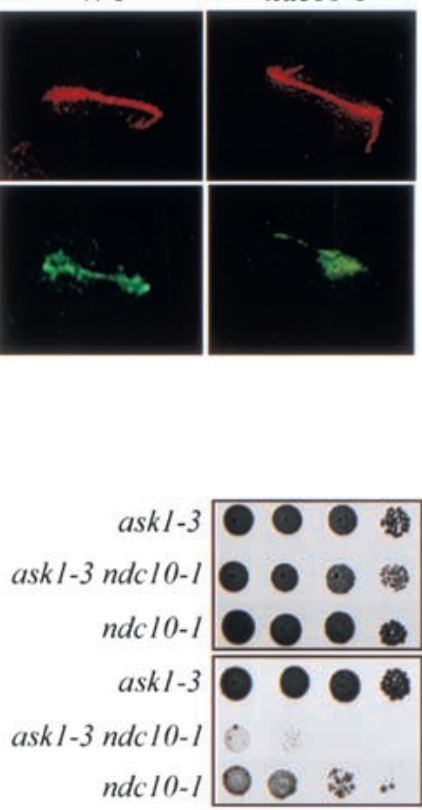

C

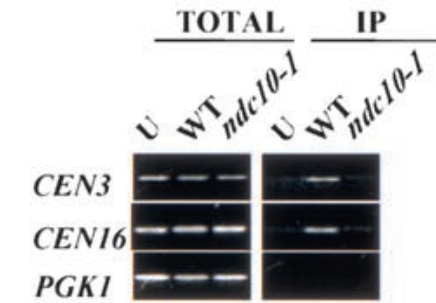

E

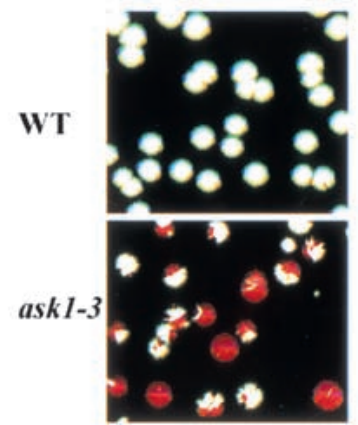

creased in ndc10-1 mutants (Fig. 4C). Consistent with the centromere binding of Ask1, ask1-3 displayed a synthetic, enhanced temperature sensitivity phenotype with $n d c 10-1$ at $30^{\circ} \mathrm{C}$ (Fig. 4D).

Given the dramatic nondisjunction phenotypes of ask1-3 mutants at its nonpermissive temperature, we anticipated that ask1 mutants would display a significant chromosome loss phenotype. To test this, we examined chromosome segregation in ask1-3 mutants with a colony color sectoring assay (Spencer et al. 1990). The strains analyzed harbored a mini-chromosome CFIII carrying SUP11 that suppresses the ade2-101 mutation present in the cells. In the absence of SUP11, the ade2101 mutation causes the accumulation of a red pigment. Loss of CFIII therefore results in a red sector. In wildtype cells, the mini-chromosome is stable and colonies appear white. However, in ask1-3 mutant cells, highly red-sectored colonies appear at semipermissive temperatures $30^{\circ} \mathrm{C}$ and $32^{\circ} \mathrm{C}$ (Fig. 4E).

\section{The centromere binding of Ask1 is microtubule} dependent

Because Ask1 associated with both the spindles and the kinetochore, it raised the possibility that the kineto- 
chore association might be dependent upon the spindle. To examine this, we carried out ChIP analysis in the presence of nocodazole, a microtubule depolymerization reagent. To eliminate cell cycle stage differences between experimental and control samples, a cdc13-1 $A S K 1-M Y C$ strain was used in these experiments because $c d c 13-1$ arrested at preanaphase. Cells were arrested at $\mathrm{G}_{1}$ with $\alpha$-factor and released at $32^{\circ} \mathrm{C}$ in the presence of nocodazole. Seventy minutes after release, cells reached $G_{2}$ and were collected. We found the centromere binding of Ask1 was significantly diminished (10-fold reduction) in cells entering $G_{2}$ phase of the cell cycle in the presence of nocodazole (Fig. 5A,F,G). The same result was also observed in wild-type cells releasing from $\mathrm{G}_{1}$ arrest into nocodazole (data not shown). Titration of the template DNA indicated that the PCR amplification was within the linear range (Fig. 5D).

In addition to depolymerizing microtubules, nocodazole treatment also activates the spindle checkpoint pathway. To distinguish whether the decrease in centromere binding is due to the loss of microtubules or to the activation of the spindle checkpoint, MAD2 was deleted

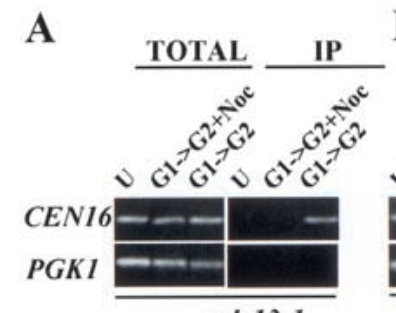

cdc13-1 cdc13-1mad2

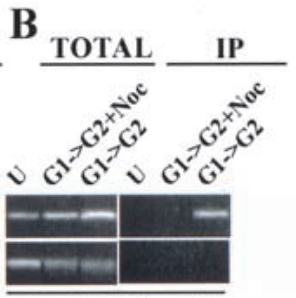

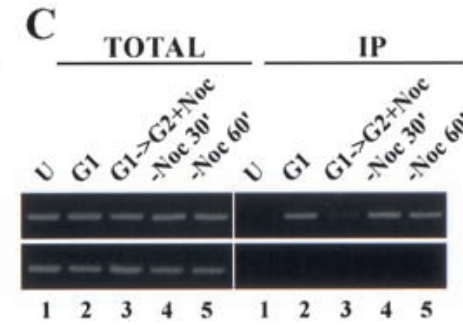

E

D

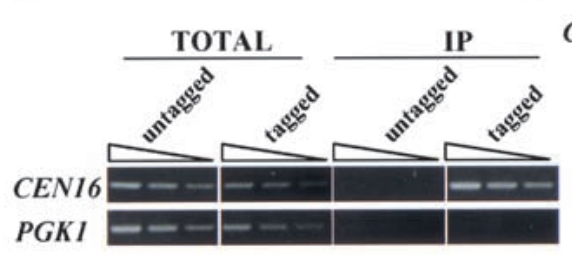

$$
\text { IP/T }(\%)
$$$$
\text { budding }
$$
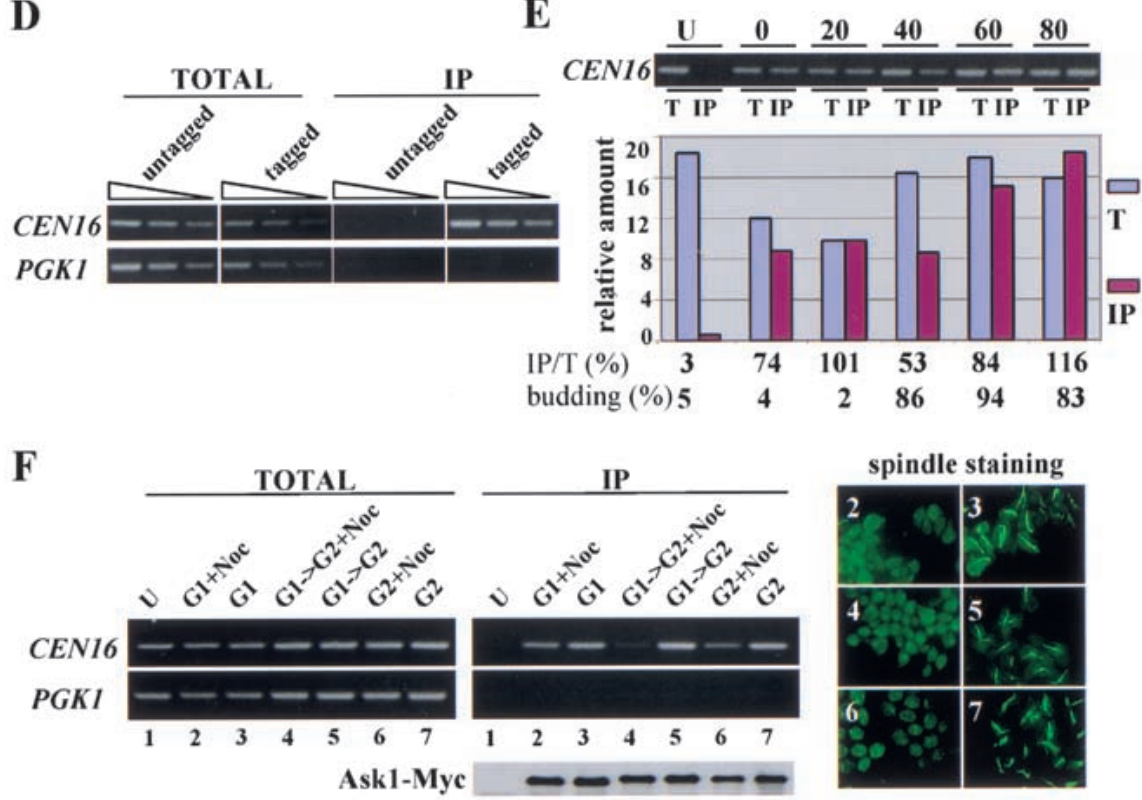

\section{G}

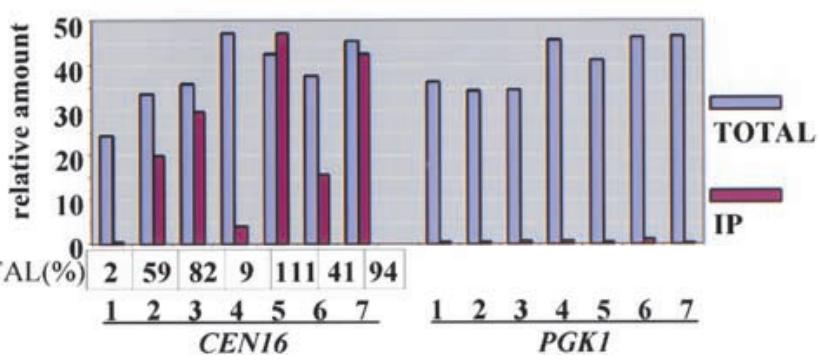

Figure 5. The association of Ask1 to the centromere requires intact microtubules. (A) Ask1 centromeric binding is inhibited by nocodazole. $\alpha$-factor-arrested $c d c 13-1$ ASK1-MYC (Y1114) cells were released into prewarmed YPD with $\left(\mathrm{G}_{1}-\mathrm{G}_{2}+\right.$ Noc $)$ or without $\left(\mathrm{G}_{1}-\mathrm{G}_{2}\right)$ nocodazole at $32^{\circ} \mathrm{C}$. Seventy minutes later, samples were collected for ChIP analysis. Untagged wildtype cells are included as a control (U). (B) Depolymerization of microtubules, not the activation of the spindle checkpoint, blocks the loading of Ask1 to centromeric DNA. $\mathrm{G}_{1}$-arrested cdc13-1 mad2 (Y1116) cells containing Ask1-Myc were released into medium containing nocodazole for 70 min and processed for ChIP analysis as above. Untagged wild-type cells are included as a control (U). (C) The nocodazole-dependent centromere binding of Ask1 is reversible. $\alpha$-factor-arrested cdc13-1 ASK1-MYC (Y1114) cells $\left(\mathrm{G}_{1}\right)$ were released into prewarmed YPD with nocodazole at $32^{\circ} \mathrm{C}\left(\mathrm{G}_{1}-\mathrm{G}_{2}+\right.$ Noc $)$. Seventy minutes later, cells were spun down and resuspended in fresh YPD at $32^{\circ} \mathrm{C}$ to remove nocodazole. Samples were collected at 30-min intervals for ChIP analysis $\left(-\right.$ Noc $30^{\prime},-$ Noc $\left.60^{\prime}\right)$. Untagged wildtype cells are included as a control $(U) .(D)$ Control showing that the PCR reactions are in the linear range. Twofold serial dilutions of the precipitated and input samples used in lanes 1 and 7 in $F$ were subjected to PCR. (E) The centromere binding of Ask1 in the cell cycle. ASK1MYC (Y1113) cells were arrested at $\mathrm{G}_{1}$ with $\alpha$-factor and then released at $30^{\circ} \mathrm{C}$. Samples were collected every $20 \mathrm{~min}$ for ChIP analysis. DNAs from total $(\mathrm{T})$ and immunoprecipitaed (IP) samples were analyzed and the PCR products were quantitated using NIH image software. Percent budding for the samples is shown below. $(F)$ The centromere binding of Ask 1 in $\mathrm{G}_{1}$ and $\mathrm{G}_{2}$-arrested cells is less sensitive to nocodazole treatment. $c d c 13-1$ ASK1-MYC (Y1114) cells were arrested in $\mathrm{G}_{1}$ with $\alpha$-factor or in $\mathrm{G}_{2}$ by incubating at $32^{\circ} \mathrm{C}$ before nocodazole was added. Seventy minutes later, samples were collected for ChIP analysis. Cells that were released from $\mathrm{G}_{1}$ to $\mathrm{G}_{2}$ were included as a control (lanes 4,5). (Bottom) The amounts of Ask1-Myc protein immunoprecipitated as determined by Western analysis. (Right) The control showing that nocodazole treatment destabilized microtubules. Shown here are anti-tubulin immunoflourescence images of cells used to prepare the DNA used in lanes 2-7. $(G)$ Quantification of the PCR reactions in $F$. PCR products in $F$ were run on a $3 \%$ agarose gel, visualized with ethidium bromide staining, and scanned for quantitation using NIH Image software. 
from the strain above and ChIP analysis was carried out. When cdc13-1 mad2 cells were released from $\mathrm{G}_{1}$ to $32^{\circ} \mathrm{C}$ in the presence of nocodazole, the centromere binding of Ask1 also decreased (Fig. 5B), indicating that the failure in Ask1 binding to centromeric DNA in the presence of nocodazole is not due to the activation of the spindle checkpoint, but due to the loss of microtubules. We conclude that the mitotic spindle is required for Ask1 binding to the centromere.

Nocodazole does not permanently inactivate the Ask1 protein because the nocodazole-dependent interference with Ask1's centromeric association is reversible. When nocodazole was removed from these cells and spindles are allowed to form and be captured by the kinetochore, Ask1 resumed its centromeric association (Fig. 5C). This provides further support for the notion that microtubules are required for the binding of Ask1 to the centromere.

To gather insight into the nature of Ask1's centromeric association, we examined this association through the cell cycle. Using synchronous cultures, we found that Ask1 remained centromere associated throughout the cycle but showed a twofold reduction as cells entered S phase (Fig. 5E). We further examined its association in cells arrested in different cell cycle stages and the effects of nocodazole during these arrests. We found that in $\mathrm{G}_{1}$ and $\mathrm{G}_{2}$-arrested cells, Ask1 bound centromeric DNA. However, treatment of these cells with nocodazloe resulted in significantly less interference, $59 \%$ and $41 \%$ residual binding, respectively (Fig. 5F,G) than observed when cells were traversing $S$ phase in the presence of nodcodazole (Fig. 5F,G). These differences are not due to different amounts of Ask1 protein immunoprecipitated under different conditions (Fig. 5F). These data suggest that either nocodazole is less effective in $G_{1}$ or $G_{2}$-arrested cells, or that traversing $S$ phase in the presence of nocodazole causes a greater sensitivity. Because nocodazole appears to be equally effective at disrupting microtubule staining under each of these conditions (Fig. 5F), the former explanation is unlikely. A plausible explanation is that kinetochore structures are disassembled as replication forks replicate centromeric DNA. After replication, kinetochores must be reassembled and reattach to the spindle to load Ask1. Thus, $S$ phase might constitute a highly nocodazole-sensitive period and is consistent with the slight reduction in binding in synchronous cultures passing through S phase (Fig. 5E).

\section{The identification of the DASH complex}

To understand the pathways in which Ask1 functions, we carried out a large-scale affinity purification using TAP-tagged Ask1 (Rigaut et al. 1999). Approximately 10 bands were specifically present after two sequential affinity purifications from the ASK1-TAP strain and were absent from strains lacking the tag. By use of mass spectrometry, several of these bands were identified as Ask1, Dam1, Duo1, Spc34, and ribosomal proteins L17A and S17A (Fig. 6A), and two additional proteins, Spc19 and Hsk1 were identified as described below. We named the complex DASH (for Dam1/Duo1, Ask1, Spc34/Spc19, Hsk1).

Dam 1 and Duol were identified previously as proteins that localized to both spindles and kinetochores like Ask1, and function to maintain spindle integrity and the fidelity of chromosome segregation (Jones et al. 1999; Cheeseman et al. 2001; He et al. 2001). The interaction between Ask1 and these two proteins was confirmed by coimmunoprecicpitation using Ask1-Myc (Fig. 6B), indicating that the association was not dependent upon the epitope tag used. The reciprocal immunoprecipitation of Duol with anti-Duol antibodies led to the coprecipitation of Ask1-Myc (Fig. 6B), further supporting the existence of a complex. The interaction was also evident by genetic analysis. We found that ask1 mutants were synthetically lethal with mutations in either DAM1 or DUO1. Double mutants of ask1-3 dam1-1 and ask1-3 duo1-2 can survive only in the presence of wild-type ASK1 (Fig. 6C). Finally, we observed that Ask1-GFP failed to localize to the spindle or kinetochore in dam1 or duo1 mutants by immunofluorescence microscopy (data not shown).

From the mass spectrometry, we also identified Spc34, a protein that copurified biochemically with the spindlepole bodies (Wigge et al. 1998). Like Ask1, Dam1, and Duo1, it also binds to both kinetochores and spindles, and its kinetochore binding is Ndc10 dependent (Wigge et al. 1998; He et al. 2001). That Spc34 is a component of DASH was confirmed by immunoprecipitation experiments carried out in strains expressing Spc34-HA (Fig. 6D).

Spc34 copurifies and colocalizes with Spc19 (He et al. 2001) and interacts with Spc19 in a two-hybrid assay (Yeast Protein Database). To test whether Spc19 is present in DASH, we precipitated Ask1-TAP from strains expressing Spc19-HA and found that Spc19 is present in the immunoprecipitates (Fig. 6E). Precipitating Spc19-HA led to the precipitation of Duo1, further confirming that Spc19 exists in DASH with Ask1 and Duol (Fig. 6E).

Ask1 interacts with a novel ORF (YKR083C) in a twohybrid assay (Yeast Protein Database). We named the protein Hsk1 (Helper of Ask1) and tagged it with the HA-epitope to test whether it was also in DASH. Immunoprecipitation experiments indicated that Hsk1 is a component of the complex (Fig. 6F).

The integrity of large complexes is often dependent upon several of their components. Therefore, we examined the complex formation in mutants of ASK1, $D A M 1$, or DUO1. Immunoprecipitation experiments were carried out in ask1-2-MYC, dam1-1 ASK1-MYC, or duo1-2 ASK1-MYC strains. Although the total amount of all three proteins was not affected significantly in the mutants, the amount of Daml and Duol in the immunoprecipitates was greatly reduced in each mutant, whereas the amount of Ask1 immunoprecipitated remained constant (Fig. 6G). This indicates that Ask1, Dam1, and Duol are all required for the integrity of the DASH complex and its function in mitosis. 
A

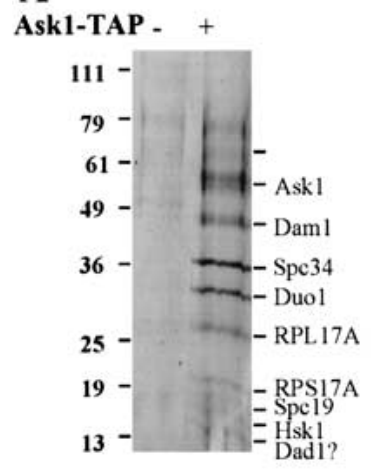

D

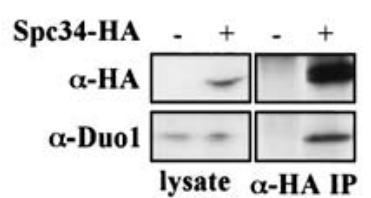

B

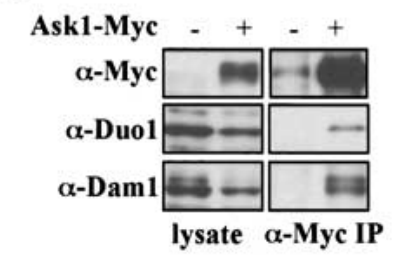

Ask1-Myc - + - +

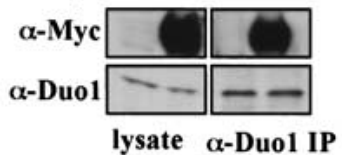

E
C
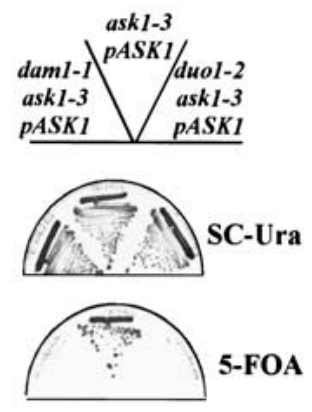
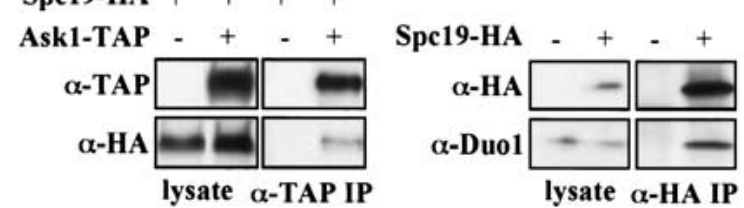

F
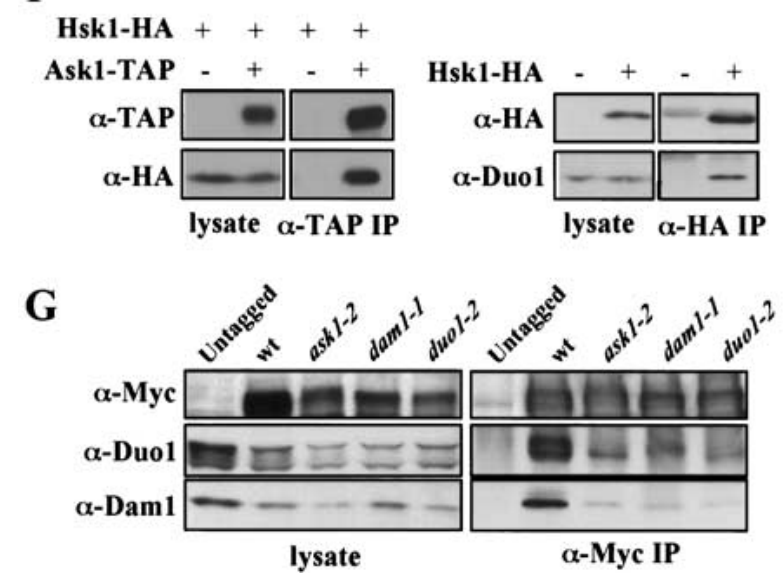

Figure 6. The identification of DASH complex. (A) TAP-purified protein extracts from $2 \mathrm{~L}$ of yeast culture from either ASK1-TAP (Y1173) or untagged strains (Y300) were resolved on $4 \%-20 \%$ SDSpolyacrylamide gels and stained with Coomassie blue. Protein bands were cut out and identified by mass spectrometry as described previously (Wang et al. 2000). Question marks indicate proteins whose identities are suspected but not yet determined. (B) Coimmunoprecipitation of Daml and Duol with Ask1-Myc. (Top) Ask1-Myc was immunoprecipitated with anti-Myc antibodies. Proteins from total protein extracts (lysate) or from the immunoprecipitated fractions (IP) were analyzed by immunoblotting, using antibodies against Dam1 and Duo1. (Bottom) The same extracts as above were immunoprecipitated with anti-Duol antibodies and Western blots were probed with anti-Myc antibodies. $(C)$ ask1-3 is synthetically lethal with dam1-1 and duo1-2. Both ask1-3 dam1-1 (Y1171) and ask1-3 duo1-2 (Y1172) containing pJBN81 (ASK1-URA3) were struck upon SC-Ura plates or SC plates containing 5-FOA. (D) Coimmunoprecipitation of Duol with Spc34. Immunoprecipitation was carried out with antiHA antibodies and Western blots were probed with anti-Duol antibodies. $(E)$ Spc19 is a component of the DASH complex. (Left) Extracts from SPC19-HA and SPC19-HA ASK--TAP strains were immunoprecipitated with anti-TAP antibodies (PAP: peroxidase-anti-peroxidase) and Western blots were probed with anti-TAP and anti-HA antibodies. (Right) Extracts from SPC19-HA and nontagged strains were immunoprecipitated with anti-HA antibodies and Western blots were probed with anti-HA and anti-Duol antibodies as

indicated. $(F)$ Hsk1 is a component of the DASH complex. (Left) Extracts from HSK1-HA and HSK1-HA ASK1-TAP strains were immunoprecipitated with anti-TAP antibodies (PAP) and Western blots were probed with anti-TAP and anti-HA antibodies. (Right) Extracts from HSK1-HA and nontagged strains were immunoprecipitated with anti-HA antibodies and Western blots were probed with anti-HA and anti-Duol antibodies. (G) ASK1, DAM1, and DUO1 are required for the formation of the DASH complex. Immunoprecipitations were carried out on extracts from ask1-2-MYC (Y1174), dam1-1 ASK1-MYC (Y1176), or duo1-2 ASK1-MYC (Y1175) strains and probed for Dam1, Duo1, and Ask1-Myc.

\section{Ip11 controls Dam1 phosphorylation}

Purification of the DASH complex revealed a number of protein bands, several of which appeared to have a heterogeneous migration pattern characteristic of phosphoproteins. This prompted us to examine the mobility of these complex members in strains mutant for protein kinases that localize to kinetochores. Ipll is a protein kinase important for chromosome segregation (Chan et al. 1993; Biggins et al. 1999) and localizes to kinetochores (He et al. 2001). We therefore examined the effect of Ipll on DASH. TAP-purified DASH complexes from either wild-type or ip11-321 mutant cells were fraction- ated on SDS-PAGE and silver stained to visualize proteins (Fig. 7A). We observed a difference in mobility of one band in ipl1 mutants. That band corresponded to the Dam 1 protein identified by mass spectrometry, suggesting Dam1 is a potential target of Ipl1.

To determine whether Daml was a phosphoprotein, Dam1 was tagged with the Myc epitope and prepared from synchronized cells. The protein was treated with phosphatase alone (AP) or with phosphatase inhibitor (PI). Dam1 migrates as a doublet and phosphatase treatment significantly reduced its mobility to the faster migrating species, indicating that Daml is a phosphoprotein (Fig. 7B). To provide further evidence that Ipl1 is 
Figure 7. Ipll controls Daml phosphorylation. (A) The mobility of DASH complex proteins is altered in ipl1 mutants. TAP-purified protein extracts from $2 \mathrm{~L}$ of yeast culture from either ASK1TAP (Y1173) or ASK1-TAP ipl1-321 mutants (Y1182) were resolved on $4 \%-20 \%$ SDS-polyacrylamide gel and silver stained. An expanded section is shown to illustrate the absence of certain bands in an ilp1 mutant strain. (B) Dam1 is a phosphoprotein. Dam1-Myc was prepared from extracts of Y1183 and treated with alkaline phosphatase in the presence or absence of phosphatase inhibitors. Proteins were then immunoblotted and probed with anti-Myc antibodies. $(C)$ Ipl1 controls the phosphorylation of Daml in vivo. Protein extracts were prepared from Y1183 (DAM1-MYC) and Y1184 (DAM1MYC ip11-321) cells synchronized in $\mathrm{G}_{1}$ with $\alpha$-factor and released into the cell cycle for the indicated time, and were then immunoblotted and probed with anti-MYC antibodies. (D) Ipll directly phosphorylates Dam1. Kinase assays were performed using GST-Ipll kinase (lanes 1,2) or GST alone as a control (lane 3). The substrate tested was the DASH complex purified from ip11-321 ASK1TAP (Y1182). The autophosphorylation of GST-Ipl1 and the phosphorylation of Daml are indicated at left. (E) Hypothetical model depicting the microtubule-dependent loading of the DASH complex to the kinetochore.

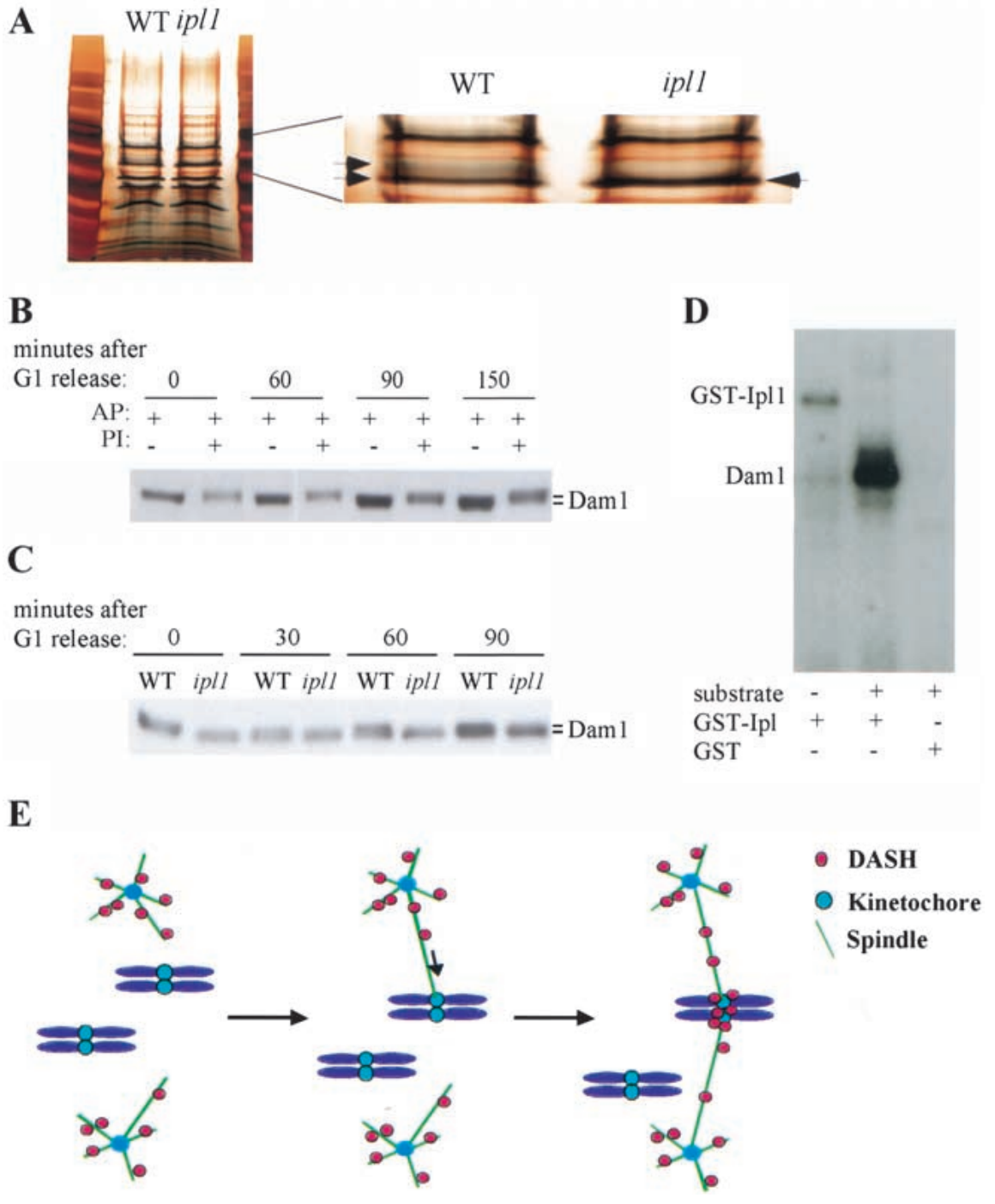

controlling Dam 1 phosphorylation in vivo, the mobility of Dam1 in wild-type and ipl1 mutants was examined in synchronized cells. The presence of the ipl1 mutation abolished the slower migrating form of Dam1 (Fig. 7C). To test whether Ipl1 phosphorylated Dam1 directly, GST and GST-Ipl1 were purified from bacteria (Biggins et al. 1999) and tested for kinase activity toward TAPpurified DASH complexes. GST-Ipll specifically phosphorylated a band corresponding to the position of Dam 1 on the gel (Fig. 7D), indicating that Dam1 is a substrate of Ipl1 and that Ipll control of Dam 1 phosphorylation in vivo is likely to be direct.

\section{Discussion}

In this study, we describe the identification of Ask1 and the DASH complex in which it resides. Genetic analysis of ask 1 mutants revealed that it plays an essential role in chromosome segregation. ASK1 and at least three addi- tional members of the DASH complex are essential genes required for proper execution of anaphase and maintenance of spindle-kinetochore integrity. The similarity in phenotype among components of DASH suggests that the entire complex is required for a common function.

We show that Ask 1 is a centromere-binding protein by several lines of evidence. First, ask1-3 mutants exhibit severe chromosome loss, a phenotype associated with kinetochore defects. Second, a genetic interaction was found between ASK1 and NDC10, a gene encoding the essential component of CBF3 kinetochore protein complex. Third, immunofluorescence staining of Ask1 shows that, in addition to associating with the mitotic spindle, it also localizes in the vicinity of the SPBs. This is consistent with the immunolocalization of many other centromere-binding proteins such as $\mathrm{Ndc10}$ and Ctf19 (Hyland et al. 1999). This localization is abolished in ndc10-1 mutants. Finally, formaldehyde cross-linking followed by chromatin immunoprecipitation reveals 
that Ask1 localizes to CEN DNA in vivo in a Ndc10dependent manner.

Ask1, and presumably the entire DASH complex, plays a critical role in chromosome segregation and maintenance of spindle-kinetochore integrity. ask1-3 mutants lose chromosomes at a very high rate at semipermissive temperatures and at their restrictive temperature, undergo massive nondisjunction. Furthermore, in ask1-3 mutant cells, we also observed an abnormal spindle in checkpoint-arrested cells in which the spindle staining between SPBs disappeared after segregation of the DNA masses. This defect is similar to that observed in dam1-1 mutants (Jones et al. 1999; Cheeseman et al. 2001), in which electron micrographs show a severe defect in spindle integrity.

The phenotypes of ask 1 mutants can best be explained through a defect in kinetochore-spindle interaction. ask1-3 mutants attempted to segregate chromosomes to daughter cells despite activation of the spindle checkpoint, suggesting cohesed sisters are pulled randomly to one of the two spindle poles and spindles are functional. Even in the absence of a spindle checkpoint in which a normal elongated spindle is observed, nondisjunction occurs at a high rate. A possible explanation for this is that, on average, one of the two spindle-kinetochore interactions on a pair of sister chromatids is defective. Whether this is a random, stochastic event or that one particular kinetochore is defective or misoriented is unknown. An alternative explanation is that chromosomes remain monoattached to a given spindle-pole body and fail to set up a bipolar attachment because they fail to release. This phenotype would be similar to that of the ipl1 mutant ( $\mathrm{T}$. Tanaka et al., in prep.), which also shows high rates of chromosome non-disjunction (Chan and Botstein 1993).

Ask1 is unique among kinetochore-binding proteins because its centromeric association is dependent upon an intact spindle. Ask1's kinetochore localization is most sensitive to spindle perturbation when cells are traversing S phase, the period in which new kinetochores are assembled and must re-establish their spindle attachment. Because Ask1 is associated with the spindle, the simplest interpretation is that Ask1 is transferred directly from the spindle to the kinetochore once kinetochores are replicated and microtubules are captured (Fig. 7E). Once Ask1 is loaded onto the kinetochore, it only partially requires the presence of microtubules to maintain kinetochore localization, indicating that it is not simply a microtubule-binding protein that is localized near the kinetochore after microtubule capture, but is actually loaded onto the kinetochore in a microtubuledependent manner. Thus, DASH requires microtubules for loading but not maintenance of its kinetochore binding. It should be noted, however, that our results cannot distinguish between loading of the Ask1 protein directly from the spindle to the kinetochore versus induced binding of Ask1 to the kinetochore upon spindle interaction.

The dynamic microtubule-dependent association of Ask1 with the kinetochore indicates that spindle binding has additional consequences for the kinetochore other than establishing a connection. DASH may be transferring information to the kinetochore in order to prepare it for future activities. How might a kinetochore benefit from DASH loading? One possibility is that DASH stabilizes the microtubule-kinetochore attachment through maturation of the kinetochore, a possibility consistent with its role in preventing nondisjunction and maintaining a short spindle during cell cycle arrest. Alternatively, DASH may act to turn off the spindle checkpoint, causing the dissociation of Mad2 and associated proteins. This would be consistent with the observation that the spindle checkpoint is maintained in an active state in ask 1 mutants. Another possibility is that DASH might help orient sister kinetochores in a back-to-back orientation to facilitate bipolar attachment once one kinetochore has captured a microtubule.

The DASH complex consists of at least ten copurifying proteins. We have identified Ask1, Dam1, Duo1, Spc34, Spc19, Hsk1, RPL17A, and RPS17A as eight of these. We have confirmed that each of these, with the exception of the ribosomal proteins, exist in a complex with at least two other components of DASH, suggesting one large complex. From sizing columns, we have detected Ask1 in a complex of $>1 \mathrm{Mda}$, which is large enough to accommodate all of these proteins (data not shown). Beside the phenotypic similarity between mutants of ASK1, $D U O 1$, and DAM1, all three proteins localize to kinetochore in a Ndc10-dependent manner (He et al. 2001). In addition, Spc34 also binds to both spindles and kinetochores, the latter in a Ndc10-dependent manner (Wigge et al. 1998; He et al. 2001). Another, as yet unidentified, component is likely to be a known protein, YDR016C (Dad1), which interacts with Duol in a two-hybrid assay (Yeast Protein Database) and has been shown recently to exist in a complex with Dam1 and Duol (Enquist-Newman et al. 2001).

The connection between Ipl1 and the DASH complex ties together two pathways important for proper control of chromosome segregation. Ipl1 has been implicated recently in controlling the sensing of tension on chromosomes. In the absence of DNA replication such as in cdc6 mutants, Pds1 degradation is delayed in a spindle checkpoint-dependent manner (Stern and Murray 2001). Unlike other aspects of spindle checkpoint function such as cell cycle arrest in response to nocodazole treatment, this aspect of the spindle-assembly checkpoint is specifically dependent on Ipl1 (Biggins and Murray 2001). The fact that Ipl1 controls Dam1 phosphorylation in vivo, most likely by direct phosphorylation, suggests that Ipl1 is controlling DASH function in some capacity. Whether this is part of Ipll's role in controlling the spindle checkpoint or a distinct role in control of chromosome segregation remains to be determined. However, as both ipl1 and ask1 mutants show severe nondisjunction phenotypes, it is likely that they are working together to ensure proper bipolar kinetochore-spindle interactions.

All of the identified members of DASH are essential proteins, indicating that it is likely to perform functions essential for mitosis. The discovery of DASH has established the existence of a new pathway controlling inter- 
actions between the spindle and the kinetochore. Furthermore, the analysis of Ask1 and the DASH complex has established a new step in kinetochore maturation and has revealed that the spindle transfers information to the newly captured kinetochore to alter its function in an important manner. The finding that Ask1 and other DASH component homologs exist in other organisms indicates that this protein complex will be conserved throughout eukaryotic evolution and is likely to play an important role in regulation of kinetochores in higher eukaryotes.

\section{Materials and methods}

\section{Yeast strains and plasmid construction}

All strains used in these experiments are isogenic with the W303-derived Y300 strain and are listed in Table 1. Gene disruptions were introduced into the Y300 background by use of standard methods. Additional strains were subsequently constructed by use of standard genetic crosses. The ASK1 deletion strain was generated by use of a 1-kb $\Delta a s k 1:: H I S 3$ PCR fragment. This fragment replaces amino acids 0-177 of the 293 amino acid ASK1 ORF with HIS3. The deletion strain was covered with $p A S K 1-C E N / A R S / U R A 3$ (pJBN81) to maintain viability.

The GFP-tagged Ask1 was generated as follows: A 490-bp fragment of Ask1 was amplified by PCR using the following primers: Ask1-23, 5'-CCCGCGGTGCCTTCAAGGGAGCAAACA GACC-3' and Ask1-27, 5'-CTAATCGATTTCTATTCGTAGA AAAATGAATG-3'. As a result, a ClaI site was introduced at the termination codon of the ASK1 gene. The resulting SacIIClaI fragment was cloned into pRS404 together with a ClaIClaI cassette containing GFP provided by Dr. John Kilmartin (MRC, Cambridge, UK). The resulting plasmid was introduced into a haploid wild-type strain Y300 at the endogenous ASK1 locus after linearization with SacI.

\section{Isolation of temperature-sensitive mutants of ASK1}

Temperature-sensitive alleles of ASK1 were generated using the PCR random mutagenesis method described previously (Wang and Elledge 1999). pJBN79 (pASK1-CEN/ARS/TRP1) was used as a template. Primers used in the PCR were as follows: Ask1-5 containing PstI site, 5'-GGTTGATCAACGTATGGA AAGAGCAACATAAGGGATTGTTGACACAAAAAATGG3', and Ask1-6 containing KpnI site, 5'-GAGCCGGTACCAT GCTGGAACTAGACCCGTACTGCTGCTGCAAAGTAGCG AATC-3'. Mutagenic PCR was carried out using 20 ng of plasmid DNA, $1 \mu \mathrm{M}$ of each primer, $5 \mathrm{mM} \mathrm{MgCl}_{2}$, and $1 \mathrm{mM}$ $\mathrm{MnCl}_{2}$. The PCR products were purified, digested with $\mathrm{KpnI}$ and PstI, and cloned into pYL61 (pJBN79 with the KpnI site on vector filled in). Approximately 10,000 Escherichia coli transformants were obtained. This library was used to transform Dask1::HIS3 covered by pJBN81 (Y1102) and Trp ${ }^{+}$transformants were selected at room temperature. They were then replica plated to plates containing $0.1 \% 5$-fluoroorotic acid (5-FOA) at $24^{\circ} \mathrm{C}$ and $37^{\circ} \mathrm{C}$ to identify temperature-sensitive mutants. From 10 temperature-sensitive clones, plasmid DNA were recovered and transformed back to confirm the phenotype. Six temperature-sensitive alleles were integrated into the ASK1 locus using two-step gene replacement, and the temperature-sensitive phenotypes of each allele could be complemented by the wild-type ASK1 gene on a CEN plasmid.
Table 1. Strains used in this study

\begin{tabular}{|c|c|}
\hline Y300 & $\begin{array}{l}\text { MATa trp-1-1 ura3-1 his3-11, } 3 \text { leu2-3, } 112 \text { ade2-1 } \\
\text { can1-100 }\end{array}$ \\
\hline Y604 & as Y300 except mecl-21 \\
\hline Y928 & as Y300 except LEU2, askl-1 \\
\hline Y974 & $\begin{array}{l}\text { as Y300 except ura3::tetO-URA3, leu2-3, } \\
\text { 112::GFP::TetR-LEU2 }\end{array}$ \\
\hline Y998 & as Y300 except PDSI-18MYC-LEU2 \\
\hline Y1101 & 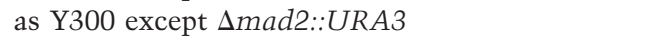 \\
\hline Y1102 & $\begin{array}{l}\text { as Y300 except } \Delta \text { ask1::HIS3 + } \\
\text { JBN81(pRS426-ASK1) }\end{array}$ \\
\hline Y1103 & as Y300 except ask1-3 \\
\hline Y1104 & as Y300 except ask1-2 \\
\hline Y1106 & as Y300 except ask1-2 $\Delta$ mad2::URA3 \\
\hline Y1107 & as Y300 except ask1-3 $\Delta$ mad2::URA3 \\
\hline Y1108 & as Y300 except PDS1-18MYC-LEU2, ask1-3 \\
\hline Y1109 & $\begin{array}{l}\text { as Y300 except ura3::tetO-URA3, } \\
\quad \text { leu2-3,112::GFP::TetR-LEU2, ask1-3 }\end{array}$ \\
\hline Y1110 & $\begin{array}{l}\text { as } \mathrm{Y} 300 \text { except ura3::tetO-URA3, } \\
\text { leu2-3,112::GFP::TetR-LEU2, ask1-3, } \\
\text { Dmad2::URA3 }\end{array}$ \\
\hline Y1111 & as Y300 except ASK1-GFP-TRP \\
\hline Y1112 & as Y300 except $A S K 1-G F P-T R P$, ndc10-1 \\
\hline $\mathrm{Y} 1113$ & as Y300 except $\Delta$ ask1::LEU2, ASK1-9MYC-HIS3 \\
\hline Y1114 & $\begin{array}{l}\text { as Y300 except } \Delta a s k 1:: L E U 2, A S K 1-9 M Y C-H I S 3 \text {, } \\
\quad c d c 13-1\end{array}$ \\
\hline Y1115 & $\begin{array}{l}\text { as Y300 except } \triangle a s k 1:: L E U 2, \text { ASK1-9MYC-HIS3, } \\
\quad n d c 10-1\end{array}$ \\
\hline Y1116 & $\begin{array}{l}\text { as Y300 except } \Delta \text { ask1::LEU2, ASK1-9MYC-HIS3, } \\
\quad \text { cdc13-1, } \Delta \text { mad2::URA3 }\end{array}$ \\
\hline Y1117 & as Y300 except CFIII, URA3, SUP11 \\
\hline Y1118 & as Y300 except CFIII, URA3, SUP11, ask1-3 \\
\hline Y1119 & as Y300 except ndc10-1 \\
\hline Y1120 & as Y300 except ask1-3 ndc10-1 \\
\hline Y1171 & as Y300 except ask1-3 dam1-1 pJBN81 \\
\hline Y1172 & as Y300 except ask1-3 duo1-2 pJBN81 \\
\hline Y1173 & as Y300 except ASK1-TAP-TRP \\
\hline Y1174 & as Y300 except ask1-2-9Myc \\
\hline Y1175 & $\begin{array}{l}\text { as Y300 except } \Delta a s k 1:: L E U 2, \text { ASK1-9MYC-HIS3, } \\
\text { duol-2 }\end{array}$ \\
\hline Y1176 & $\begin{array}{l}\text { as Y300 except } \Delta a s k 1:: L E U 2, \text { ASK1-9MYC-HIS3, } \\
\quad \text { dam1-1 }\end{array}$ \\
\hline Y1177 & as Y300 except SPC34-HA \\
\hline Y1178 & as $\mathrm{Y} 300$ except SPC19-HA \\
\hline Y1179 & as Y300 except SPC19-HA, ASK1-TAP-TRP \\
\hline Y1180 & as $\mathrm{Y} 300$ except $H S K 1-H A$ \\
\hline Y1181 & as Y300 except HSK1-HA, ASK1-TAP-TRP \\
\hline Y1182 & as Y300 except ip11-321, ASK1-TAP-TRP \\
\hline Y1183 & as Y300 except DAM1-MYC-TRP1 \\
\hline Y1184 & as Y300 except ipl1-321, DAM1-MYC-TRP1 \\
\hline
\end{tabular}

\section{Cytological techniques}

FACS analysis was performed as described previously (Desany et al. 1998). Immunofluorescence microscopy using both antitubulin and anti-GFP antibodies was performed after formaldehyde fixation as described (Sanchez et al. 1996). Cells were fixed by $5 \%$ formaldehyde for $0.5 \mathrm{~h}$ and then stained by anti-GFP polyclonal (1:2000 dilution, provided by Dr. Silver, Harvard Medical School and Dana Farber Cancer Institute, Boston, MA) and anti-tubulin Yol1/34 (1:50 dilution, Desany et al. 1998) antibodies after methanol/acetone treatment. Other immunofluorescence microscopy using anti-tubulin antibodies was done as described previously (Desany et al. 1998). DAPI was used for 
staining of DNA after fixation. Observation of TetR-GFP was performed directly on a Zeiss Axioskop after cells were fixed for $5 \mathrm{~min}$.

\section{Protein purification}

Protein extracts from a 2-L yeast culture of OD 1.2 were prepared using RIPA buffer ( $150 \mathrm{mM} \mathrm{NaCl}, 50 \mathrm{mM}$ Tris-Cl, $5 \mathrm{mM}$ EDTA, $0.5 \%$ Triton X-100), and subsequently, TAP purification was carried out as described (Rigaut et al. 1999). After centrifugation to obtain the supernatant, Tris- $\mathrm{Cl}(\mathrm{pH} 8.0)$ was added to a final concentration of $10 \mathrm{mM}$ and NP40 was added to a final concentration of $0.1 \%$. The extracts were then subjected to twostep affinity purification. After a 2 -h incubation with IgG Sepharose $(400 \mu \mathrm{L})$ at $4^{\circ} \mathrm{C}$, the beads were washed three times with IPP150 (10 mM Tris-Cl at $\mathrm{pH} 8.0,150 \mathrm{mM} \mathrm{NaCl}$, and $0.1 \%$ NP-40), once with TEV buffer (IPP150 containing $0.5 \mathrm{mM}$ EDTA and $1 \mathrm{mM}$ DTT), and incubated in 1-mL TEV buffer containing $100 \mathrm{U}$ of TEV protease (GIBCO BRL) at room temperature for $2 \mathrm{~h}$ in a column. The eluate was diluted to $4.8 \mathrm{~mL}$ with calmodulin-binding buffer (IPP150 containing $10 \mathrm{mM}$ $\beta$-mercaptoethanol, $1 \mathrm{mM} \mathrm{Mg}$-acetate, $1 \mathrm{mM}$ imidazole, $2 \mathrm{mM}$ $\mathrm{CaCl}_{2}$ ), $3.6 \mu \mathrm{L} 1 \mathrm{M} \mathrm{CaCl}_{2}$ and $200 \mu \mathrm{L}$ of calmodulin beads were added and incubated at $4^{\circ} \mathrm{C}$ for $1 \mathrm{hr}$. After washing, bound proteins were eluted (five times, $200 \mu \mathrm{L}$ each) with calmodulin elution buffer (IPP150 containing $10 \mathrm{mM} \beta$-mercaptoethanol, 1 $\mathrm{mM}$ Mg-acetate, $1 \mathrm{mM}$ imidazole, and $2 \mathrm{mM}$ EGTA). Purified proteins were precipitated with TCA and analyzed by $4 \%-20 \%$ SDS-PAGE, followed by Coomassie blue staining and silver staining.

\section{Kinase assay}

TAP-purified DASH complex from an ipl1-321 ASK1-TAP strain was eluted in $200 \mu \mathrm{L}$ kinase buffer $(50 \mathrm{mM}$ Tris- $\mathrm{Cl}$ at $\mathrm{pH}$ 8.0, $100 \mathrm{mM} \mathrm{NaCl}, 2 \mathrm{mM}$ EGTA, $1 \mathrm{mM}$ imidazole, $25 \mathrm{mM}$ $\beta$-glycerophosphate, $1 \mathrm{mM}$ DTT, $10 \mathrm{mM}$ ATP, $5 \mathrm{mM} \mathrm{MgCl}_{2}, 2.5$ $\mu \mathrm{Ci}\left[\gamma^{32}\right.$-P $]$ ATP) and $1 \mu \mathrm{g}$ GST or GST-Ipll on beads were added to the reaction for $20 \mathrm{~min}$ at $30^{\circ} \mathrm{C}$ as described (Biggins et al. 1999).

\section{Chromatin immunoprecipitations}

Chromatin immunoprecipitation assays were conducted essentially as described previously (Aparicio et al. 1997; Zou and Stillman 2000). Ask1-Myc was immunoprecipitated by the monoclonal antibody 9E10. Primers for CEN3, CEN16, and the AT-rich region near PGK1 are the same as described (Meluh and Koshland 1997).

The nocodazole treatment of the cells were carried out as follows: cells were arrested with $\alpha$-factor for $3 \mathrm{~h}$, or $32^{\circ} \mathrm{C}$ incubation for $2 \mathrm{~h}$ before being spun down and resuspended in YPD containing $15 \mu \mathrm{g} / \mathrm{mL}$ nocodazole and $1 \%$ DMSO. YPD containing $1 \%$ DMSO was used as control. Seventy minutes later, the cells were spun down for ChIP analysis.

\section{Acknowledgments}

We thank K. Nasmyth, P. Hieter, J. Kilmartin, and S. Biggins for strains; P. Silver, D.G. Drubin, and G. Barnes for antibodies; and K. Nasmyth and T. Tanaka for sharing unpublished results. We also thank X. He, M. Winey, A. Hyman, and members of the Elledge laboratory for comments and helpful discussions. We thank L. Zou and D. Zhang for sharing their technical expertise. This work was supported in part by a National Institute of
Health Grant. S. J. E. is an investigator with the Howard Hughes Medical Institute and a Welch professor of biochemistry.

The publication costs of this article were defrayed in part by payment of page charges. This article must therefore be hereby marked "advertisement" in accordance with 18 USC section 1734 solely to indicate this fact.

\section{References}

Alcasabas, A.A., Osborn, A.J., Bachant, J., Hu, F., Werler, P.J.H., Bousset, K., Kanji Furuya, K., Diffley, J.F.X., Carr, A. and Elledge, S.J. 2001. Mrc1 transduces DNA replication stress signals to activate Rad53. Nat. Cell. Biol.. 3: 958-965.

Amon, A. 1999. The spindle checkpoint. Curr. Opin. Genet. Dev. 9: 69-75.

Aparicio, O.M., Weinstein, D.M., and Bell, S.P. 1997. Components and dynamics of DNA replication complexes in $S$. cerevisiae: Redistribution of MCM proteins and Cdc45p during S phase. Cell 91: 59-69.

Biggins, S. and Murray, A.W. 2001. The budding yeast protein kinase Ipl1/Aurora allows the absence of tension to activate the spindle checkpoint. Genes \& Dev. 15: 3118-3129.

Biggins, S., Severin, F.F., Bhalla, N., Sassoon, I., Hyman, A.A., and Murray, A.W. 1999. The conserved protein kinase Ipl1 regulates microtubule binding to kinetochores in budding yeast. Genes \& Dev. 13: 532-544.

Cai, M. and Davis, R.W. 1990. Yeast centromere binding protein $\mathrm{CBF}$ 1, of the helix-loop-helix protein family, is required for chromosome stability and methionine prototrophy. Cell 61: 437-446.

Chan, C.S. and Botstein, D. 1993. Isolation and characterization of chromosome-gain and increase-in- ploidy mutants in yeast. Genetics 135: 677-691.

Cheeseman, I.M., Enquist-Newman, M., Muller-Reichert, T., Drubin, D.G., and Barnes, G. 2001. Mitotic spindle integrity and kinetochore gunction linked by the Duolp/Dam1p complex. J. Cell Biol. 152: 197-212.

Chen, R.H., Waters, J.C., Salmon, E.D., and Murray, A.W. 1996. Association of spindle assembly checkpoint component XMAD2 with unattached kinetochores. Science 274: 242246.

Ciosk, R., Zachariae, W., Michaelis, C., Shevchenko, A., Mann, M., and Nasmyth, K. 1998. An ESP1/PDS1 complex regulates loss of sister chromatid cohesion at the metaphase to anaphase transition in yeast. Cell 93: 1067-1076.

Cohen-Fix, O., Peters, J.M., Kirschner, M.W., and Koshland, D. 1996. Anaphase initiation in Saccharomyces cerevisiae is controlled by the APC-dependent degradation of the anaphase inhibitor Pds1p. Genes \& Dev. 10: 3081-3093.

Connelly, C. and Hieter, P. 1996. Budding yeast SKP1 encodes an evolutionarily conserved kinetochore protein required for cell cycle progression. Cell 86: 275-285.

Desany, B.A., Alcasabas, A.A., Bachant, J.B., and Elledge, S.J. 1998. Recovery from DNA replicational stress is the essential function of the S-phase checkpoint pathway. Genes \& Dev. 12: 2956-2970.

Doheny, K.F., Sorger, P.K., Hyman, A.A., Tugendreich, S., Spencer, F., and Hieter, P. 1993. Identification of essential components of the S. cerevisiae kinetochore. Cell 73: 761774.

Elledge, S.J. and Davis, R.W. 1990. Two genes differentially regulated in the cell cycle and by DNA- damaging agents encode alternative regulatory subunits of ribonucleotide reductase. Genes \& Dev. 4: 740-751.

Enquist-Newman, M., Cheeseman, I.M., Van Goor, D., Drubin, 
D.G., Meluh, P.B., and Barnes, G. 2001. Dad1p, third component of the duolp/dam $1 \mathrm{p}$ complex involved in kinetochore function and mitotic spindle integrity. Mol. Biol. Cell 12: 2601-2613.

Farr, K.A. and Hoyt, M.A. 1998. Bublp kinase activates the Saccharomyces cerevisiae spindle assembly checkpoint. Mol. Cell. Biol. 18: 2738-2747.

Funabiki, H., Yamano, H., Kumada, K., Nagao, K., Hunt, T., and Yanagida, M. 1996 Cut2 proteolysis required for sister-chromatid seperation in fission yeast. Nature 381: 438-441.

Goh, P.Y. and Kilmartin, J.V. 1993. NDC10: A gene involved in chromosome segregation in Saccharomyces cerevisiae. I. Cell Biol. 121: 503-512.

Gorbsky, G.J. and Ricketts, W.A. 1993. Differential expression of a phosphoepitope at the kinetochores of moving chromosomes. J. Cell Biol. 122: 1311-1321.

Goshima, G. and Yanagida, M. 2000. Establishing biorientation occurs with precocious separation of the sister kinetochores, but not the arms, in the early spindle of budding yeast. Cell 100: 619-633.

Hardwick, K.G. and Murray, A.W. 1995. Mad1p, a phosphoprotein component of the spindle assembly checkpoint in budding yeast. J. Cell Biol. 131: 709-720.

Hardwick, K.G., Weiss, E., Luca, F.C., Winey, M., and Murray, A.W. 1996. Activation of the budding yeast spindle assembly checkpoint without mitotic spindle disruption. Science 273: 953-956.

He, X., Asthana, S., and Sorger, P.K. 2000. Transient sister chromatid separation and elastic deformation of chromosomes during mitosis in budding yeast. Cell 101: 763-775.

He, X., Rines, D.R., Espelin, C.W., and Sorger, P.K. 2001. Molecular analysis of kinetochore-microtubule attachment in budding yeast. Cell 10: 195-206.

Hegemann, J.H. and Fleig, U.N. 1993. The centromere of budding yeast BioEssays 15: 451-460.

Hoyt, M.A. and Geiser, J.R. 1996. Genetic analysis of the mitotic spindle. Annu. Rev. Genet. 30: 7-33.

Hoyt, M.A., Totis, L., and Roberts, B.T. 1991. S. cerevisiae genes required for cell cycle arrest in response to loss of microtubule function. Cell 66: 507-517.

Hoyt, M.A., He, L., Loo, K.K., and Saunders, W.S. 1992. Two Saccharomyces cerevisiae kinesin-related gene products required for mitotic spindle assembly. J. Cell Biol. 118: 109120.

Hwang, L.H., Lau, L.F., Smith, D.L., Mistrot, C.A., Hardwick, K.G., Hwang, E.S., Amon, A., and Murray, A.W. 1998. Budding yeast Cdc20: A target of the spindle checkpoint. Science 279: 1041-1044.

Hyland, K.M., Kingsbury, J., Koshland, D., and Hieter, P. 1999. Ctf19p: A novel kinetochore protein in Saccharomyces cerevisiae and a potential link between the kinetochore and mitotic spindle. J. Cell Biol. 145: 15-28.

Jensen, S., Segal, M., Clarke, D.J., and Reed, S.I. 2001. A novel role of the budding yeast separin Esp1 in anaphase spindle elongation. Evidence that proper spindle association of esp 1 is regulated by pds1. J. Cell Biol. 152: 27-40.

Jiang, W., Lechner, J., and Carbon, J. 1993. Isolation and characterization of a gene (CBF2) specifying a protein component of the budding yeast kinetochore. I. Cell Biol. 121: 513519.

Jones, M.H., Bachant, J.B., Castillo, A.R., Giddings, T.H., and Winey, M. 1999. Yeast Damlp is required to maintain spindle integrity during mitosis and interacts with the Mps1p kinase. Mol. Biol. Cell 10: 2377-2391.

Kim, S.H., Lin, D.P., Matsumoto, S., Kitazono, A., and Matsumoto, T. 1998 Fission yeast Slp1: An effector of the Mad2- dependent spindle checkpoint. Science 279: 1045-1047.

Lechner, J. 1994. A zinc finger protein, essential for chromosome segregation, constitutes a putative DNA binding subunit of the Saccharomyces cerevisiae kinetochore complex, Cbf3. EMBO I. 13: 5203-5211.

Lechner, J. and Ortiz, J. 1996. The Saccharomyces cerevisiae kinetochore. FEBS Lett. 389: 70-74.

Li, R. and Murray, A.W. 1991. Feedback control of mitosis in budding yeast. Cell 66: 519-531.

Meluh, P.B. and Koshland, D. 1995. Evidence that the MIF2 gene of Saccharomyces cerevisiae encodes a centromere protein with homology to the mammalian centromere protein CENP-C. Mol. Biol. Cell 6: 793-807.

1997. Budding yeast centromere composition and assembly as revealed by in vivo cross-linking. Genes \& Dev. 11: 3401-3412.

Meluh, P.B., Yang, P., Glowczewski, L., Koshland, D., and Smith, M.M. 1998. Cse4p is a component of the core centromere of Saccharomyces cerevisiae. Cell 94: 607-613.

Michaelis, C., Ciosk, R., and Nasmyth, K. 1997. Cohesins: Chromosomal proteins that prevent premature separation of sister chromatids. Cell 91: 35-45.

Ortiz, J., Stemmann, O., Rank, S., and Lechner, J. 1999. A putative protein complex consisting of Ctf19, Mcm21, and Okp1 represents a missing link in the budding yeast kinetochore. Genes \& Dev. 13: 1140-1155.

Pangilinan, F. and Spencer, F. 1996. Abnormal kinetochore structure activates the spindle assembly checkpoint in budding yeast. Mol. Biol. Cell 7: 1195-1208.

Pellman, D., Bagget, M., Tu, Y.H., Fink, G.R., and Tu, H. 1995. Two microtubule-associated proteins required for anaphase spindle movement in Saccharomyces cerevisiae. J. Cell Biol. 130: $1373-1385$.

Pidoux, A.L. and Allshire, R.C. 2000. Centromeres: Getting a grip of chromosomes. Curr. Opin. Cell Biol. 12: 308-319.

Rigaut, G., Shevchenko, A., Rutz, B., Wilm, M., Mann, M., and Séraphin, B. 1999. A generic protein purification method for protein complex characterization and proteome exploration. Nat. Biotechnol. 17: 1030-1032.

Roof, D.M., Meluh, P.B., and Rose, M.D. 1992. Kinesin-related proteins required for assembly of the mitotic spindle. J. Cell Biol. 118: 95-108.

Sanchez, Y., Desany, B.A., Jones, W.J., Liu, Q., Wang, B., and Elledge, S.J. 1996. Regulation of RAD53 by the ATM-like kinases MEC1 and TEL1 in yeast cell cycle checkpoint pathways. Science 271: 357-360.

Saunders, W.S. and Hoyt, M.A. 1992. Kinesin-related proteins required for structural integrity of the mitotic spindle. Cell 70: 451-458.

Spencer, F., Gerring, S.L., Connelly, C., and Hieter, P. 1990 Mitotic chromosome transmission fidelity mutants in Saccharomyces cerevisiae. Genetics 124: 237-249.

Stern, B.M. and Murray, A.W. 2001. Lack of tension at kinetochores activates the spindle checkpoint in budding yeast. Curr. Biol. 11: 1462-1467.

Strunnikov, A.V., Kingsbury, J., and Koshland, D. 1995. CEP3 encodes a centromere protein of Saccharomyces cerevisiae. J. Cell Biol. 128: 749-760.

Uhlmann, F., Lottspeich, F., and Nasmyth, K. 1999. Sister-chromatid separation at anaphase onset is promoted by cleavage of the cohesin subunit Scc1. Nature 400: 37-42.

Wang, H. and Elledge, S.J. 1999. DRC1, DNA replication and checkpoint protein 1, functions with DPB11 to control DNA replication and the S-phase checkpoint in Saccharomyces cerevisiae. Proc. Natl. Acad. Sci. 96: 3824-3829.

Wang, Y. and Burke, D.J. 1995. Checkpoint genes required to 
delay cell division in response to nocodazole respond to impaired kinetochore function in the yeast Saccharomyces cerevisiae. Mol. Cell. Biol. 15: 6838-6844.

Wang, Y., Cortez, D., Yazdi, P., Neff, N., Elledge, S.J., and Qin, J. 2000. BASC, a super complex of BRCA1-associated proteins involved in the recognition and repair of aberrant DNA structures. Genes \& Dev. 14: 927-939.

Wigge, P.A., Jensen, O.N., Holmes, S., Soues, S., Mann, M., and Kilmartin, J.V. 1998. Analysis of the Saccharomyces spindle pole by matrix-assisted laser desorption/ionization (MALDI) mass spectrometry. J. Cell Biol. 141: 967-977.

Winey, M. and O'Toole, E.T. 2001. The spindle cycle in budding yeast. Nat. Cell Biol. 3: 23-27.

Yamamoto, A., Guacci, V., and Koshland, D. 1996 Pdslp, an inhibitor of anaphase in budding yeast, plays a critical role in the APC and checkpoint pathway(s). J. Cell Biol. 133: 99110.

Zou, L. and Stillman, B. 2000. Assembly of a complex containing Cdc45p, replication protein $\mathrm{A}$, and $\mathrm{Mcm} 2 \mathrm{p}$ at replication origins controlled by S-phase cyclin-dependent kinases and Cdc7p-Dbf4p kinase. Mol. Cell Biol. 20: 3086-3096. 


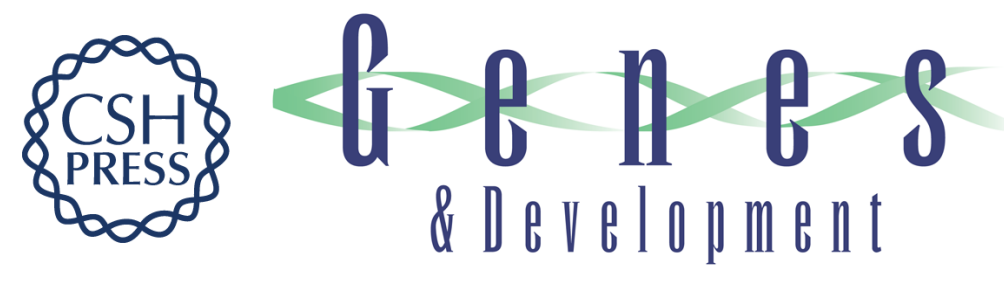

\section{The mitotic spindle is required for loading of the DASH complex onto the kinetochore}

Yumei Li, Jeff Bachant, Annette A. Alcasabas, et al.

Genes Dev. 2002, 16:

Access the most recent version at doi:10.1101/gad.959402

References This article cites 60 articles, 36 of which can be accessed free at: http://genesdev.cshlp.org/content/16/2/183.full.htmI\#ref-list-1

License

Email Alerting

Receive free email alerts when new articles cite this article - sign up in the box at the top Service right corner of the article or click here.

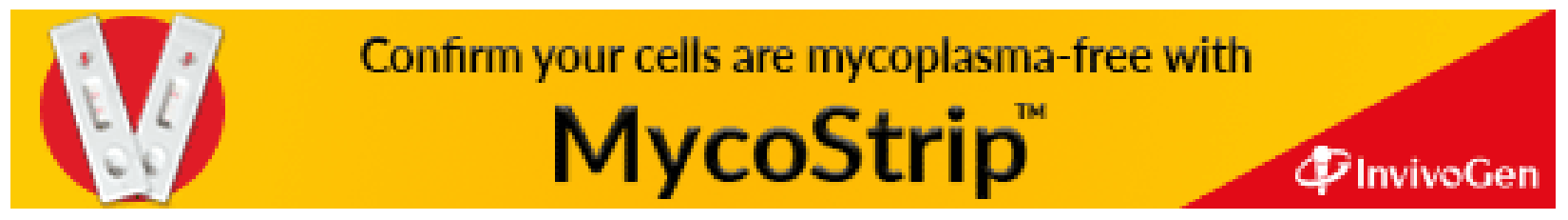

